\title{
Modelling Pellet-Clad Mechanical Interaction During Extended Reduced Power Operation in Bonded Nuclear Fuel
}

\author{
T.A. Haynes ${ }^{1}$, J.A. Ball ${ }^{2}$, J.H. Shea ${ }^{2}$, M.R. Wenman ${ }^{1 *}$ \\ Department of Materials and Centre for Nuclear Engineering, Imperial College London, Exhibition Rd, \\ London, SW7 2AZ \\ Nuclear Technology Branch, EDF Energy Generation, Barnett Way, Barnwood, Gloucester, GL4 3RS \\ Corresponding Author: m.wenman@imperial.ac.uk, 0044 (0)20 75946763
}

\section{Highlights}

- A finite element model for pellet-clad mechanical interaction in gas reactor fuel.

- A sliver of fuel with reduced elastic modulus was bonded to the cladding.

- Extended reduced power operation at $70 \%$ for one month was investigated.

- The importance of pellet-clad friction and irradiation creep of fuel is noted.

- Pellet crack geometry had a small effect upon the interaction.

\begin{abstract}
A $2 \mathrm{D}-r \theta$ model of pellet-clad mechanical interaction in advanced gas-cooled reactor fuel is presented. An incipient $5 \mu \mathrm{m}$ crack is introduced into the inner surface of cladding bonded to a detachable sliver of fuel. Micro-cracking in the sliver is accounted for through a reduced elastic modulus. A test transient consisting of a hold at $70 \%$ power for 720 hours was applied to the model. The competing effects of the closure of pellet cracks due to irradiation creep in inner regions of the pellet during extended low power operation, and that of thermal creep in the cladding whilst at reduced power alleviating this are investigated. In colder elements, the effect of irradiation creep dominates. In hotter elements, the effect of cladding creep at low power dominates. It was found that adjusting factors related to the pellet shape were unimportant; the sliver thickness, sliver shape and initial pellet crack width had only a small effect upon the extent of PCMI. Adjusting factors relating to the shape of the incipient crack such as the crack radius and depth had a significant effect; as did adjusting the elastic modulus reduction factor accounting for ladder cracking in the sliver and the coefficient of friction used throughout the model. The resulting model was able to predict the trend in average clad bore crack depth with axial position in the core observed in post irradiation examination.
\end{abstract}


Pellet-clad interaction (PCI) failures were first observed in boiling water reactors (BWRs) in the early 1960s [1, 2], and have since been observed in pressurised water reactors (PWRs) [3-5], Canadian heavy water (CANDU) reactors [6], Russian VVER reactors [7, 8] and British advanced gas-cooled reactors (AGRs) [9, 10]. A number of approaches have been taken to mitigate PCI, these have included lubrication of the fuel-cladding gap in CANDU and BWR reactors [11]; pure / low-alloy zirconium liners in BWRs [12]; and, the implementation of operating limits for both PWRs and AGRs [2, 13], the latter being supported by computational modelling, postirradiation examination (PIE) [14, 15] and experimental campaigns [3, 16-19].

PIE has revealed the following features in spent AGR fuel, summarised in Fig. 1:

- large radial cracks from the centre of the annular fuel pellet to the cladding inner surface;

- the formation in some reactor channel positions, early in life, of a strong bond between the cladding and pellet [10];

- circumferential cracks some distance from the fuel-cladding surface, leaving a sliver of fuel attached to the cladding [14], through which the macroscopic radial cracks continue [10];

- some instances of radial microcracking along fuel grain boundaries (known as ladder cracks) in this adherent sliver; and

- the deposition of a carbonaceous deposit on the cladding [15].

One key difference between PWR and AGR fuel performance is that the clad and fuel in AGRs are thought to remain bonded in all but the most severe transients [10,20,21], whilst the fuel and clad surfaces in light water reactors (LWRs) can slide under friction [5, 21-23] and only become bonded at higher burn-ups, typically in the range 45-50 GWd/tU [24-26]. Experiments on $\mathrm{UO}_{2}$ and $\mathrm{AGR}$ cladding have found that a bond is formed between the steel and fuel by around 1875 hours (equivalent to approximately $5 \mathrm{GWd} \mathrm{tU}^{-1}$ ) at $650{ }^{\circ} \mathrm{C}$ [27]. Another difference, is that since PWR fuel pellets contain no central bore, circumferential cracking in PWRs appears to commence at the boundary between regions of the pellet in which creep can and cannot occur [4, 23]. AGR fuel is exposed to a greater range of operating conditions than PWR fuel due to a greater temperature change along the reactor's cooling channels (as a result of the $\mathrm{CO}_{2}$ coolant) and the implementation of on-load re-fuelling at some stations, during which reactor thermal output is cycled between $30 \%$ and $70 \%$ over a period of several hours. During operation, the pellets take a 'wheatsheaf' shape [22, 28, 29] with the over-lying cladding obtaining a 'bamboo' shape $[3,13,30]$. PCI in LWRs results in cracks in the cladding at the pellet ends, where a radial crack through the fuel pellet impinges upon the cladding [3]. AGRs fuel pellets have a larger chamfer and PIE has shown CBCs at all positions along the pellet, including the waist [31].

Modelling PCI represents a significant challenge in that although the numerous drivers of PCI are well known $[32,33]$, they are inter-dependent, and obtaining a single parameter representing the propensity of a fuel pin to fail has given significant difficulties [23]. PCI in water-cooled reactors is thought to be dominated by stress corrosion cracking caused by fission products [34-36]. In AGRs, attention has focused upon the mechanical features in what has been termed pellet-clad mechanical interaction (PCMI), one of the key aspects of which is the differential thermal expansion between the stainless steel cladding and the ceramic fuel bonded to it. 
Two dimensional $(r-z)$ models can be grouped into two categories, axisymmetric finite element (FE) models of either a single pellet $[33,37]$ or half a pin $[30,38,39]$; and the industrial codes such as ENIGMA and METEOR $[33,40]$ (known as '1.5D models' [37]), which consist of de-coupled axisymmetric transverse slices of fuel and cladding. Whilst the axisymmetric models are able to model a whole pin and frequently include smeared pellet crack models to account for the change of shape of fuel due to pellet cracking and its relocation, they are unable to model azimuthal pellet crack opening. The '1.5D' models often include empirical or semi-empirical models for azimuthal stress concentration and pellet 'wheatsheafing'. Early FE software was developed for 2D plane stress or plane strain analyses [41] and the earliest $r-\theta$ PCMI models reflect this [20, 42]. Whilst it can be argued that the free end of the pellet is under conditions approaching plane stress, the surrounding cladding is likely to be experiencing a multi-axial stress due to the ridging described above and the fact it is a continuous tube. For this reason, plane strain was chosen in the late 1980s / early 1990s to represent the mid pellet plane [43]. Contemporary codes such as EDF Energy's version of ENIGMA [44] modelled axisymmetric transverse slices of fuel and cladding; under conditions of contact, a frictional force balance was maintained between the pellet and cladding and there was no coupling of displacement or stress between adjacent slices [13]. This model of uniform axial strain in transverse slices of fuel and coupling to the cladding when in contact was adopted to build generalised plane strain FE models of typically 1/16th $r-\theta$ slices of cladding [13, 22, 23, 45]; again, these models represent the pellet waist, not the pellet end, where the most severe PCMI occurs in LWRs. 3D models, for example TOUTATIS in the ALCYONE suite [3, 13, 45], typically consider only one or two pellets and assume that the pellet has cracked into approximately equal-sized sections. Locking boundary conditions are applied, whereby the pellet and clad displacements are equal at the top and bottom of the pellet if the clad and pellet are in contact at any point. The models are therefore able to model both 'wheatsheafing' and the azimuthal opening of the pellet but currently do not model crack propagation in the cladding.

Whilst the mechanical loading of the cladding differs in AGRs and PWRs due to the formation of a strong cladfuel bond, higher coolant temperatures, an annular fuel pellet and a wider operating envelope. The result is however similar: stress concentration opposite a radial crack. In an AGR, the cladding experiences local creep ductility exhaustion [20,46, 47], resulting in a "clad bore crack" (CBC) ahead of the radial crack in the pellet. The lower power density and higher temperatures of the graphite-moderated AGRs means that thermal creep is more important in the cladding than irradiation creep [48].

The initiation mechanism for CBCs in AGR fuel is not currently well understood. PIE has revealed a population of these cracks in AGR fuel and research has focused upon predicting crack growth from a given incipient crack length since it is known that the vast majority of CBCs are benign [49]. Out of pile adhesion tests on unirradiated fuel and PIE have revealed that the bonding layer between the cladding and fuel in AGR fuel consists of oxide phases containing chromium, caesium and enriched in manganese and silicon with respect to the cladding [27]; manganese is associated with hardening in austenitic stainless steel. Short (10 $\mu \mathrm{m})$ incipient intergranular cracks have also been observed in the internal bore of the soft zirconium liner introduced to mitigate against PCI in the BWR system, these are associated with a hardened layer of metal rich in fission products thought to be introduced by fission recoil [50]. It should be noted that the location of the incipient cracks in the 
zirconium liner does not always correspond the that of the radial pellet cracks but are observed at the mid-pellet position [51], the former possibly due to pellet relocation.

This paper details the development of a two-dimensional $(r-\theta)$ model for pellet-clad interaction in advanced gas-cooled reactors (PELICAN) at Imperial College London. It has been applied to steady state operation and a simple test transient of extended reduced power operation. The model differs from previous FE models of PCMI in that the stress concentration ahead of cracks in the cladding has been modelled and the effect of a sliver of fuel bonded to the cladding considered. This work found that modelling the microscopic ladder cracks in the sliver of fuel substantially reduces the creep strain accrued ahead of the CBC tip and therefore the propensity of the clad bore crack to propagate. It is noted that the geometric shape of the crack fragments had little effect upon the extent of PCMI.

\section{$2 \quad$ Methodology}

2.1 Model design

A 2D model of a $1 / 8^{\text {th }}$ segment of fuel, shown in Fig. 2, was built in the commercial FE code Abaqus 6.11 and consisted of three parts modelled under conditions of generalised plane strain: a section of fuel pellet, accounting for the outer twelfth of the annular pellet; separate detachable sliver of fuel, with reduced elastic modulus to account for ladder cracking (the hair-line micro-cracking in the sliver); and stainless steel cladding. It is assumed that small power changes have resulted in eight radial cracks extending the entire axial length of the pellet, forming eight segments. A CBC is introduced to the cladding by reducing the elastic modulus of the material, in a section ahead of the radial crack at the centre of the pellet segment, by a factor $k_{C B C}$, detailed in Table 1. For values of $k_{C B C}$ less than $1.0 \times 10^{-5}$, the stress ahead of the $\mathrm{CBC}$ section was found to be insensitive to $k_{C B C}$ although some residual elastic modulus was required to maintain model stability. Quadrilateral, quadratic, coupled temperature-displacement elements were used and a mesh convergence carried out. Element sizes range from $60 \mu \mathrm{m}$ on the outer corner of the cladding to $25 \mathrm{~nm}$ at the CBC tip. The mesh ahead of the crack tip is shown in Fig. 3. The elastic modulus reduction factor, $k_{L C}$, which accounts for ladder cracking in the adherent sliver, has previously been determined by tuning NIMROD (ENIGMA's model for CBC growth in bonded PCMI) against clad wall thinning strains observed in PIE and validated against power cycling experiments in the Halden test reactor [10]. Following bonding between the cladding and detachable sliver, the composite formed is free to move over the pellet fragment.

The boundary conditions consist of:

- a coolant temperature boundary on the outside of the cladding;

- zero angular displacement at the $0^{\circ}$ and $45^{\circ}$ lines (lines 1 and 2 in Fig. 3);

- radial displacement on the inner surface of the pellet section, (accounting for pellet sintering and inexorable swelling);

- zero angular displacement on the outside of the cladding during initial creep down to prevent buckling;

- initially, zero displacement along the radial crack through the fuel and sliver. 
Closure of the ladder cracks in the sliver was not modelled and their behaviour is modelled solely through the reduced elastic modulus. The sliver is therefore significantly softer in compression than it should be (in NIMROD, the closure of the ladder cracks is modelled by returning the elastic modulus to its un-cracked value). Output from EDF Energy's ENIGMA code (version 5.13) was used as the source of the radial displacement boundary condition at the pellet segment inner surface and allowed the thermo-mechanical and nuclear performance of the hotter inner portion of the pellet to be modelled by the ENIGMA code and included in this FE model. The surface and body heat flux values were adjusted to account for expansion/contraction of the pellet and the differing neutron absorbance, volumetric rating and plutonium breeding in the outer regions of the fuel by using the volumetric rating factors from ENIGMA's output. A coolant pressure of 4.1 MPa was applied to the outside surface of the cladding whilst an internal pressure was applied to surfaces able to open.

Three behaviours are used for contact between parts in the model; 'sliding', 'bonded' and 'uncracked'; the steps at which these are applied are given in Table 1. Initially, the cladding-fuel gap was assumed to be open and the detachable sliver and pellet assumed to be in perfect contact with no thermal impedance (the 'uncracked' behaviour). During early operation, the clad creeps down onto the sliver and 'sliding' behaviour was assumed between the cladding and sliver. Following cladding creep down, the interaction between the detachable sliver and cladding changes from 'sliding' to 'bonded' to represent clad-fuel bonding. Next, the azimuthal boundary condition on the radial crack was removed and replaced with a 'sliding' interaction; this represents the situation where cladding is bonded to a radially cracked pellet. The ladder cracks in the detachable sliver were then introduced by the gradual reduction in the elastic modulus; the detachment of the sliver from the pellet was modelled by changing the interaction between the detachable sliver and pellet section to 'bonded' and then 'sliding'. Finally, an incipient CBC is introduced by slowly reducing the elastic modulus of a small region of cladding shown in Figs. 2-3.

\subsection{Overview of finite element analysis approach}

Abaqus is an implementation of the FE approach which has been widely applied in a number of fields of engineering. The purpose of finite element analysis (FEA) is to solve partial differential equations, in this case Newton's second law and temperature diffusion, on a complex geometry. For a coupled temperaturedisplacement simulation, the partial differential equations are the differential forms of Newton's second law and Hooke's law together with Poisson's equation. The material properties are a function of burn-up, stress and temperature.

\subsection{Determination of strains}

The implicit non-linear model developed here determined the total true stain, $\Delta \varepsilon_{T O T}$, at each node from the sum of the elastic, plastic, thermal and creep strains (1) in each of the three principal directions (radial, hoop and axial):

$\Delta \varepsilon_{T O T}=\Delta \varepsilon_{E L}+\Delta \varepsilon_{P L}+\Delta \varepsilon_{T H}+\Delta \varepsilon_{C R}$ 
The elastic strain, $\Delta \varepsilon_{E L}$, is determined from the elastic modulus of the material, which was assumed to be isotropic. The temperature variation ( $T$, in $\mathrm{K}$ ) of the elastic modulus ( $E$, in $\mathrm{GPa}$ ) is given by (2). The values of the constants are taken from EDF Energy datasheets [52, 53], representative values of which are given in [39].

$E=E_{0}+E_{1} T+E_{2} T^{2}$

In $\mathrm{UO}_{2}$, the value of the Poisson's ratio, $v$, used decreased from 0.320 at $0^{\circ} \mathrm{C}$ to 0.295 at $2300^{\circ} \mathrm{C}$ and took the form given in (3) [53]. In stainless steel, a constant value of 0.325 was assumed [39].

$v=v_{0}+v_{1} T+v_{2} T^{2}$

The instantaneous plastic strain in the cladding is determined by calculating the $0.2 \%$ yield stress $\left(\sigma_{Y}\right.$, in $\left.\mathrm{MPa}\right)$ as a function of the average irradiation temperature $\left(T_{A V}\right.$, in $\left.\mathrm{K}\right)$, the bulk clad helium concentration $([\mathrm{He}]$ in appm) and the current temperature ( $T, \mathrm{~K})$ using (4) [52]. A correlation (5) is used to determine the bulk clad helium concentration from the Westcott flux, ( $W$, in $10^{20}$ neutrons) and burn-up ( $B U$, in $\mathrm{GWd} / \mathrm{tU}$ ) [54]. The first term in (5) accounts for thermal capture of neutrons by ${ }^{10} \mathrm{~B}$, the second by ${ }^{58} \mathrm{Ni}$ and the third of both species by fast flux. The Westcott flux itself is determined from a correlation (6) to the burn-up and enrichment $\left(\%{ }^{235} \mathrm{U}\right)$ [54]:

$\sigma_{Y}=Y_{1}[H e]^{Y_{2}} T_{A V}^{Y_{3}} e^{-Y_{4} T}$

$[H e]=H_{1}\left(1-e^{-H_{2} W}\right)+H_{3} W^{2}+H_{4} B U$

$W=\frac{B U}{\% 235_{U}}\left(W_{1}+W_{2} B U^{2}\right)$

Using the yield stress and the equivalent stress $\left(\sigma_{e q}\right.$, in MPa), the equivalent instantaneous plastic strain $\left(\Delta \varepsilon_{e q, P L}\right)$ is determined using (7) [52]:

$\Delta \varepsilon_{e q, P L}=-P_{1}+P_{2}\left(\frac{\sigma_{e q}}{\sigma_{Y}}\right)^{P_{2}} \quad \Delta \varepsilon_{e q, P L}>0$

The increment of equivalent creep strain in the cladding, $\Delta \varepsilon_{e q, C R}$, in a time-step ( $\left.\Delta t, \mathrm{~s}\right)$ is given by (8); this is the same relation as reported in [39]. The first term accounts for diffusion creep and the second for dislocation creep. Irradiation creep is not considered in AGR stainless steel cladding in part due to the lower neutron flux in AGRs compared to LWR designs:

$\Delta \varepsilon_{e q, C R}=\left(C_{1} \sigma_{e q}^{C_{2}} e^{-C_{3} / R T}+C_{4} \sigma_{e q}^{C_{5}} e^{-C_{6} / R T}\right) \Delta t$

As equations 4-8 are derived for bulk material, their applicability at length scales smaller than the characteristic grain size $(10 \mu \mathrm{m})$ at the $\mathrm{CBC}$ tip is unclear. 
The thermal strain was determined from the coefficient of thermal expansion, $\alpha$, which takes the form of (9) and is given in [39]. It should be noted that Abaqus uses a temperature-integrated version of the thermal conductivity to calculate the thermal strain. The thermal strain was assumed to be isotropic and applied in each principal direction.

$\alpha=\alpha_{0}+\alpha_{1} T+\alpha_{2} T^{2}$

\section{$2.4 \quad$ Thermal properties}

The specific heat capacity $\left(c_{p}\right.$, in $\left.\mathrm{J} \mathrm{kg}^{-1} \mathrm{~K}^{-1}\right)$ in both materials was given by an expression of the form (10), with values given by [39]:

$c_{p}=C P_{0}+C P_{1} T$

Thermal conductivity of the fuel $\left(\lambda\right.$, in $\left.\mathrm{J} \mathrm{kg}^{-1} \mathrm{~K}^{-1}\right)$ is an important parameter in determining the fuel temperature and therefore expansion. In order to introduce a temperature and burn-up dependence to the model, an ENIGMA simulation was set up consisting of a number of transients and periods of steady state operation. The transients and initial power-raise were used to determine the temperature dependence of the conductivity and the dwells allowed a long-term burn-up correction factor to be determined. The thermal conductivity of the fuel is given by the product of a temperature dependent term and burn-up dependent term (11) and the constants used are given in table 2. In the cladding, it takes the value given in [39] and no burn-up dependent term was included.

$\lambda=\left(\lambda_{T 0}+\lambda_{T 1} T+\lambda_{T 2} T^{2}\right)\left(\lambda_{B 0}+\lambda_{B 1} B U+\lambda_{B 2} B U^{2}\right)$

\subsection{Contact properties}

Three behaviours were used for contact between parts in the model: 'sliding', 'bonded' and 'uncracked'. Cohesive behaviour was chosen for all interactions except for 'sliding'. Small sliding was used for 'sliding' contact and finite sliding otherwise. Surface to surface discretisation was used throughout. A small amount of friction (coefficient of friction, $\mu=0.2)$ was assumed in the 'sliding' interaction and a very large amount $(\mu=$ 6.00 ) assumed in the 'bonded' interaction in order to stabilize the model.

For the 'bonded' and 'sliding' interactions, the model used a simple gap conductance model based upon the temperature-dependent conductivity, $\lambda(T)$, of a mixture of $90 \%$ helium and $10 \%$ xenon determined by Hashimoto et al. using the shock tube method for temperatures in the range of 250 to $5000 \mathrm{~K}$ [55]. Assuming a surface roughness, $r_{0}$, of $2.5 \mu \mathrm{m}$, the gap conductance, $G$, of a gap of width $r$ is given by (12):

$G=\frac{\lambda(T)}{r+r_{0}}$

Since the model developed here considers only the conductivity of a helium-xenon gas fill-mixture, the same model was used for all interfaces except for the sliver-pellet interaction prior to sliver detachment where the thermal conductivity of un-irradiated fuel was assumed. 
User-defined field variables, implemented in a USDFLD subroutine of Abaqus, were used to provide a number of parameters for use in the FE model based upon the output in the previous step. Parameters calculated included:

- the burn-up, irradiation time and average irradiation temperature.

- the helium concentration in the cladding, based upon a correlation to the burn-up and ${ }^{235} \mathrm{U}$ enrichment.

- the thermal conductivity of the fuel via a temperature and burn-up dependent correlation.

- the factor, $k_{C B C}$, to reduce the elastic modulus in the $\mathrm{CBC}$ during its introduction. This is a linear decrease from ' 1 ' to a fixed value of $1.0 \times 10^{-6}$. The elastic modulus of the $\mathrm{CBC}$ region was given by that of the fuel, multiplied by $k_{C B C}$.

- the factor, $k_{L C}$, to reduce the elastic modulus in the sliver to account for ladder cracking, this is a linear decrease from ' 1 ' to a fixed default value of 0.03 . The elastic modulus of the sliver was given by that of the sliver, multiplied by $k_{L C}$.

The steps at which the parameters $k_{C B C}$ and $k_{L C}$ were used are shown in Table 1. The bonding interaction was introduced approximately 100 hours following contact and initially had a negligible effect - the hoop stress in bulk cladding (point A, Fig. 3) increased from -17.9 MPa to -18.7 MPa. Ladder cracking was introduced 1.0x10 s (2778 hours) following contact. This was considered sufficient time for ladder cracks to form as a result of transients associated with refuelling outages. It was assumed that the time between clad and fuel contact, bonding and the initiation of the $\mathrm{CBC}$ was the same for all elements. $\mathrm{CBC}$ introduction was complete at $2.0 \times 10^{7}$ s (231 days) following contact and this assumption was based upon PIE showing a typical incubation stringer mean burn-up of 5-8 $\mathrm{GWd} \mathrm{tU}^{-1}[56]$. The values of $k_{C B C}$ and $k_{L C}$ were reduced over 5.0x10 $\mathrm{s}$, a similar period to that between refuelling campaigns.

\subsection{Operating conditions \& simulations run}

An AGR fuel stringer consists of 7-8 fuel elements stacked vertically and numbered from the bottom. The FE model was run at linear ratings and temperatures considered typical of elements 2-8 at a typical AGR with little carbon deposition on the fuel pins (see Fig. 4). Fuel element 1 was not modelled as the clad-fuel bond is not as frequently seen due to the lower operating temperature. In addition, a model was run in which no CBC was introduced; a model in which ladder cracks were not introduced; and a simulation in which the pellet crack was not able to open. The test transient modelled consisted of a slow ramp [at $3 \% \mathrm{~h}^{-1}$ ] from $100 \%$ to $70 \%$ power, followed by a period of steady operation for 30 days and then a slow ramp [at $3 \% \mathrm{~h}^{-1}$ ] back to $100 \%$ power. The ramp rate was based upon a recommendation from a station that a ramp rate of $1 \%$ every 20 minutes can be applied at these power levels.

The geometry of CBCs and the underlying fuel cracks observed in PIE varies considerably. The default values reported here are considered typical, but reflect only a small set of pins examined under PIE some years after being removed from reactor. In order to determine the sensitivity of the model to input variables, the following changes were made to the default values: 
- Adjusting the sliver 'curvature factor'. This was defined as the ratio of the thickness of the sliver at the radial crack (point C, Fig. 3) to that well away from the CBC (point B, Fig. 3). The sliver curvature factor was varied from $0.11(30 \mu \mathrm{m} / 270 \mu \mathrm{m})$ to $9.0(270 \mu \mathrm{m} / 30 \mu \mathrm{m})$. The default value for a uniform thickness was 1.0.

- Varying the sliver thickness between 15 and $300 \mu \mathrm{m}$ (default value used was $60 \mu \mathrm{m}$ ).

- Varying the width of the radial crack in the pellet from $1.3 \mu \mathrm{m}$ to $6.3 \mu \mathrm{m}$ (default value used was 2.5 $\mu \mathrm{m})$.

- Varying the CBC depth from 2 to $50 \mu \mathrm{m}$ and crack tip radius from 0.25 to $1.0 \mu \mathrm{m}$ (default values used were $5 \mu \mathrm{m}$ and $0.5 \mu \mathrm{m}$ respectively). The $\mathrm{CBC}$ depth default value was based upon the threshold for measurement used in PIE.

- Varying $k_{L C}$ from 0.003 to 1.0 (representing a sliver with no ladder cracks). The default value of 0.03 was derived from the validation of NIMROD.

- Varying the coefficient of friction from 0.0 (frictionless) to 1.2 ; the default value was 0.2 , based upon the value used in a CEGB clad ratcheting model [57]. In addition, a simulation was run in which the radial cracks were not able to open.

The simulations were carried out on a single core of a 3.50 GHz Intel Xeon E5-2637 processor running on a computer with $64 \mathrm{MB}$ of RAM. Parallelisation was not used due to the relatively poor parallelisation capability of Abaqus 6.11. The simulations took between 5.6 and $18.0 \mathrm{~h}$ to run and each created between 31 and $73 \mathrm{~GB}$ of data.

\section{$3 \quad$ Results}

\subsection{Cladding creep-down}

Fig. 5 shows the pellet-clad gap size and temperature drop during creep down for fuel element 5 and Fig. 6 the time to gap closure and initial contact for each fuel element. For element 5 , the gap begins to close at 32 followed by contact at $55.4 \mathrm{~h}$. This is well before the fuel reaches full power at $64 \mathrm{~h}$. The time to contact decreases rapidly with element number (and therefore coolant temperature) from $2268 \mathrm{~h}$ in element 2 to $41 \mathrm{~h}$ in element 8 and shows the strong dependence of the cladding creep strain rate upon coolant temperature in the AGR. The maximum gap opening increases with element number from $37.4 \mu \mathrm{m}$ in element 2 to $56.3 \mu \mathrm{m}$ in element 8 . The values are much more similar than those for the time to contact and reflect the increasing thermal expansion with coolant temperature.

\subsection{Fuel conditioning prior to test transient}

This section concerns the state of the fuel during the initial ramp to full power and the subsequent hold. Fuel conditioning is defined as the period it takes for stresses in both the pellet and cladding to reach a constant value following a transient. Fig. 7 shows that the high compressive hoop stress of $-82.5 \mathrm{MPa}$ caused by the expansion of the cladding during initial start-up and subsequent creep down gave rise to creep strains that are compressive in the hoop direction. In element 5 , the hoop stress in bulk cladding passes from compressive to tensile at 110 days as the pellet-clad gap is closed and the pellet expands into the clad. Tensile stresses of approximately 3.6 
$\mathrm{MPa}$ in bulk cladding and 42.0 MPa at the CBC tip occurred under steady state operation at full power, and gave rise to further creep strain in the hoop direction, this time positive in sign. Generally, a constant hoop stress was reached by steady creep to counteract the expansion of the fuel. During crack introduction between 181 and 239 days, the hoop stress in the sliver increased from -1.4 to -0.8 MPa. Under steady state operation, the sliver hoop stress was much lower than in the cladding and typically around $0.6 \mathrm{MPa}$.

\subsection{Pellet motion during the test transient}

Fig. 8 shows the azimuthal and radial motion of the pellet fragment underneath the clad-sliver composite during the transient. The inserts show the azimuthal displacement and the schematic shape of the fuel pellet. During the down-rate, the fuel retreated and the pellet crack closed; during the up-rate, the opposite occurred. As a result of irradiation creep in the inner regions of the pellet during the hold at $70 \%$ power, the pellet cracks in the inner regions closed which meant that the radial displacement of the sliver inner surface was $0.9 \mu \mathrm{m}$ greater at the end of the transient compared to the start. In addition, the pellet crack opened more during the up-rate than it closed during the down rate $(4.7 \mu \mathrm{m}$ compared to $1.9 \mu \mathrm{m})$. The contact pressure in element 5 varied between 4.0 and 5.6 $\mathrm{MPa}$ during the transient, meaning that the composite and pellet section remained in contact during the whole transient and that the total hoop strain in the composite was driven by the radial displacement at the base of the sliver. The small additional radial displacement as a result of irradiation creep of the inner regions of the pellet has a significant effect upon the stress in the cladding during the up-rate and is discussed in the next section.

\subsection{Behaviour of bulk material during the test transient}

During the transients modelled, the pellet and cladding remained in contact due to the coolant pressure. There was therefore an additional constraint upon the clad-sliver composite - i.e. that it must be in contact with the pellet at all times. This means the radii of the outer surface of the pellet and the inner surface of the sliver were the same. This in turn placed constraints on the change in total strain (elastic + plastic + creep + thermal), in both the hoop and radial directions, to ensure sliver contact with the pellet. Whilst the thermal strain is imposed by the nature of the transient, the elastic strain is able to change in order to fulfil the total strain constraint. In turn, the elastic strains are relaxed when creep occurs and evolve with time. It should be noted that no plastic strain was observed during any simulation. Fig. 9a shows the small difference between the decrease in thermal strain in the cladding and the change in the total strain resulting from the clad-composite contact. This small difference is responsible for the elastic strains in the cladding and the the hoop stress reversals observed during rating changes. During the down-rate (Fig. 9a), the reduction in the total hoop strain was initially slightly greater than the reduction in thermal strain (by a maximum difference in strain of $0.0057 \%$ ). This resulted in a small negative elastic hoop strain in the bulk cladding and the compressive stress observed until $9.7 \mathrm{~h}$ into the downrate. Fig. $9 \mathrm{~b}$ shows that until $6.4 \mathrm{~h}$ into the up-rate, the thermal strain increased more than the total hoop strain and so there was a compressive hoop stress in the cladding. Following $6.4 \mathrm{~h}$, the radial motion of the pellet into the cladding increased, resulting in a tensile stress in the cladding as a result of the greater total strain. The additional total hoop strain of $0.010 \%$ due to irradiation creep in the pellet, during the hold at low power, gave rise to a tensile hoop stress of 29.2 $\mathrm{MPa}$ in the cladding. Should the hoop stress in the cladding become 
significantly compressive during a rating change, the composite and underlying fuel would separate and the constraint upon the total strain would be removed.

Fig. 10 compares the hoop stress in bulk cladding for each fuel element during the up-rate. All elements started the up-rate in tension, with the initial stress generally decreasing with increasing element number. During the down-rate, the hoop stress decreased before increasing (as explained by Fig. 9b) however, for higher fuel element numbers (which are also higher in the core), the decrease was greater. The result was that elements 7 and 8 ended the transient in compression. The larger decrease was a result of creep in the cladding during the hold at reduced power.

\subsection{Radial Stress profile in the cladding}

Fig. 11 shows the hoop stress in the cladding for three different scenarios. At the end of the up-rate, the radial profile of the hoop stress in bulk cladding between two adjacent CBCs was fairly constant, increasing from 25.4 $\mathrm{MPa}$ on the inside of the cladding to $31.3 \mathrm{MPa}$ on the outside. Ahead of a radial pellet crack, in the absence of a $\mathrm{CBC}$, the hoop stress increased from 54.9 $\mathrm{MPa}$ to $63.8 \mathrm{MPa}$ at a distance of $2.2 \mu \mathrm{m}$ into the cladding before decreasing to $34.3 \mathrm{MPa}$ on the outer surface. In the presence of a $\mathrm{CBC}$, the peak in the hoop stress, and hence maximum principal stress of $130.3 \mathrm{MPa}$, occurred around $0.6 \mu \mathrm{m}$ ahead of the $\mathrm{CBC}$ tip. The sensitivity of the maximum principal stress to the $\mathrm{CBC}$ depth and radius is discussed in section 3.9. The stress concentration associated with the $\mathrm{CBC}$ is highly localised, the hoop stress reached the average of the peak and outer surface values within $2.4 \mu \mathrm{m}$ of the $\mathrm{CBC}$ tip and $7.5 \mu \mathrm{m}$ from the base of the cladding in the absence of a CBC. Finally, the thickness of the cladding was the same regardless of the presence of a either a $\mathrm{CBC}$ or a radial fuel crack. This is evidence that early in life there was no clad thinning associated with either the $\mathrm{CBC}$ or radial crack in the fuel and can be explained by insufficient time/stress for creep to occur.

No plasticity was observed in the cladding of any fuel element modelled and the hoop stress was generally higher $0.5 \mu \mathrm{m}$ ahead of the $\mathrm{CBC}$ tip than at the $\mathrm{CBC}$ tip. The peak in the hoop stress ahead of the CBC tip was accompanied by a peak in the radial stress at this position. The result was that the von Mises equivalent stress, and hence the creep strain at the end of the simulation, was lower than at the $\mathrm{CBC}$ tip $(2.7 \%$ compared to $10.9 \%$ at the $\mathrm{CBC}$ tip).

\subsection{Accrual of creep strain at the CBC tip}

Fig. 12 shows the creep strain accrued at the $\mathrm{CBC}$ tip during each stage of the test transient. The total creep strain accrued over the three-month period (shown in Fig. 12) increased from $1.2 \%$ in element 2 to $8.5 \%$ in elements 6 and 7. The lower creep strain found in element 8 was due to reduced fuel swelling. In all elements except element 8 , the creep strain accrued in the 30 days following the transient was greater than the 30 days preceding it and that from the low power hold. The ratio of strain accrued in the 30 days post to pre-transient was greatest in element 4 (3.28) and least in element $8(0.5)$. The decreased ratio in elements 7 and 8 was the result of a post-transient hoop stress reversal resulting from the compressive stress at the end of the up-rate (Fig. 10). In all cases except element 8 , the creep strain accrued at the $\mathrm{CBC}$ tip was greater for the up-rate than the down-rate. This is a result of the stress reaching its maximum at the end of the up-rate, when the fuel is at its 
hottest. Comparing the creep strain accrued in the absence of low power operation, the low power operation resulted in increased creep strain being accrued at the $\mathrm{CBC}$ tip in all elements except elements 6 and 7, increasing by $83 \%$ in element 4 and by $326 \%$ in element 8 . In element 7 , the creep strain decreased by $18 \%$ as a result of the low power operation.

\subsection{The effect of azimuthal pellet sliding}

Fig. 8 shows that the pellet crack closed during the down-rate and opened during the up-rate and steady state operation. For models with no $\mathrm{CBC}$, the steady state hoop stress in the ligament was $7.8 \mathrm{MPa}$ in the model in which pellet azimuthal motion was supressed and $21.7 \mathrm{MPa}$ when it was permitted. The maximum hoop stress at the end of the up-rate was 54.9 MPa with azimuthal sliding and 36.3 MPa without. Increasing the coefficient of friction between the pellet and sliver resulted in more of the pellet fragment's azimuthal motion being transferred to the base of the sliver and increased the hoop stresses at the $\mathrm{CBC}$ tip during rating changes. Fig. 13 shows that increasing the coefficient of friction from 0.0 to 1.2 increased the equivalent creep strain accrued at the $\mathrm{CBC}$ tip during the up-rate from $1.7 \%$ to $11.0 \%$, the default value of 0.2 resulted in a strain of $3.8 \%$.

\subsection{The effect of ladder cracking}

Fig. 13 shows that increasing the elastic modulus of the sliver to account for ladder cracking increased the equivalent creep strain accrued at the $\mathrm{CBC}$ tip during the up-rate. Increasing $k_{L C}$ from 0.015 to 0.045 (through the default value of 0.03 ) increased the strain accrued at the CBC tip during the uprate from $2.7 \%$ to $4.4 \%$. This can be explained by force equilibrium at the clad-sliver boundary, i.e. increased stress in the sliver led to an increased stress in the bulk cladding and this stress then leads to increased stress at the CBC tip. Fig. 14a shows that the hoop stress experienced in the sliver during rating changes was much greater in the model in which ladder cracks were not introduced. The maximum hoop stress in the sliver during the up-rate was $170.6 \mathrm{MPa}$ in the model with no ladder cracks and 3.0 MPa in the model with ladder cracks introduced using the default value of $k_{L C}=0.03$. The initial heat-up (prior to ladder crack introduction) gave rise to a tensile stress of $424.1 \mathrm{MPa}$. Fig. 14b shows that due to the higher stresses in the cladding, the creep strain accrued at the CBC tip was much greater when ladder cracks are not introduced. By the end of the up-rate, the creep strain was $40.6 \%$ in the presence of ladder cracks and $2.9 \%$ in their absence.

\subsection{The effect of geometric assumptions}

Adjusting factors relating to fuel cracking, which are easier to measure in PIE, resulted in smaller changes than those relating to $\mathrm{CBC}$ geometry (Fig. 13). Reducing the sliver thickness below its default value of $60 \mu \mathrm{m}$ to 15 $\mu \mathrm{m}$ reduced the $\mathrm{CBC}$ tip creep strain by $12 \%$. Increasing the sliver thickness to $240 \mu \mathrm{m}$ resulted in a maximum increase of $11 \%$. The sliver curvature had an even smaller effect. Generally, PIE shows that slivers tend to be thinner close to the $\mathrm{CBC}$. Making the sliver three times thinner closer to the $\mathrm{CBC}$ increased the creep strain accrued during the up-rate by 5\%, whilst slivers that are thicker near to the $\mathrm{CBC}$ resulted in a small decrease in creep strain. The maximum change in creep strain due to changing the fuel crack width at creep down was negligible, at $4 \%$. This is reassuring since this parameter is very difficult to determine experimentally and the value used in this work is an assumption. 


\subsection{Validation against CBC statistics}

Over 1,200 transverse sections of AGR cladding have been examined at Windscale and Berkeley Laboratories since the 1980s and any CBCs deeper than a threshold depth of $5 \mu \mathrm{m}$ measured. Fig. 15 compares the creep strain accrued at the $\mathrm{CBC}$ tip, predicted by this model, to the average $\mathrm{CBC}$ depth above measured in transverse sections taken from fuel elements at different axial core positions. The average depth was calculated by taking an average of these values for each sample and then taking an average of that average across all samples from fuel elements in a given axial position. No CBCs have been measured in either element 1 or 2. Elements 3 to 6 show progressively deeper average $\mathrm{CBC}$ depths, with the maximum average depth of $13.6 \mu \mathrm{m}$ in element 6 . The depth then decreases in elements $7(13.2 \mu \mathrm{m})$ and $8(10.8 \mu \mathrm{m})$. The total creep strain predicted by this model shows a similar pattern of the greatest creep strain in elements 6 and 7 (8.48\% and 8.46\% respectively). Elements 2-5 showed lower creep strains of 1.2 to $3.6 \%$ and element 8 gave a creep strain of $2.25 \%$. CBC statistics show that the average CBC depth is slightly greater in element 8 compared to 5 (10.8 and $10.6 \mu \mathrm{m})$ whilst PELICAN (the FE model) predicts a slightly greater creep strain at the $\mathrm{CBC}$ tip in element 5 compared to 8 (3.6\% and $2.3 \%)$.

\section{$4 \quad$ Discussion}

The AGR system demonstrates a wider range of operating temperatures than the typical LWR and significant differences are seen along each vertical fuel channel. In addition, a range of linear power ratings are encountered. Three key factors have been shown to be important in understanding PCMI across the range of conditions investigated:

- irradiation creep in the inner pellet during the low power hold.

- thermal creep in the cladding during the low power hold.

- comparatively small differences between the changes in thermal strain and total strain in the cladding driven by the radial displacement of the pellet.

Despite these factors being derived for the AGR system, it is anticipated that they will be important in loadfollowing LWRs.

Irradiation creep in the inner regions of the fuel during reduced power operations is responsible for the closure of the smoothed pellet cracks modelled by EDF's version of ENIGMA. Following their partial closure, the thermal strain imposed by the up-rate results in a small increase in the outward radial surface displacement of the pellet compared to the down-rate. In element 5 , the additional radial displacement was only $0.9 \mu \mathrm{m}$, compared to a clad thickness of almost $400 \mu \mathrm{m}$. Whilst the clad-sliver composite and pellet fragment are in contact, the thermal strain and total strain in the cladding is made up by elastic strains. The stress is therefore dependent upon very small differences between changes in the thermal strain and the total hoop strain (resulting from pellet radial displacement).

Thermal creep in the cladding, whilst it is in tension during the low power hold, increases its circumference. During the up-rate this alleviates the effect of the additional outward radial displacement of the pellet due to irradiation creep. Fig. 10 shows that, in the hottest fuel elements (7 and 8), this results in a compressive hoop 
stress in the clad at the end of the up-rate and reduces the accrual of creep strain at the CBC tip following the transient as a result of the post-transient stress reversal.

In the lower elements, which tend to be colder but higher rated, the effect of irradiation creep in the inner regions of the pellet dominates and large tensile hoop strains are seen in the cladding. For example element 2 is assumed to operate at clad temperature of $496{ }^{\circ} \mathrm{C}$ and pellet power of $14.0 \mathrm{~kW} \mathrm{~m}{ }^{-1}$ during the low power hold and a post-up-rate cladding hoop stress of $68.1 \mathrm{MPa}$ occurs. In comparison, the response of the bulk cladding in the hotter elements is dominated by thermal creep of the cladding during the low power hold. For example, element 8 is assumed to see conditions of $630^{\circ} \mathrm{C}$ (clad) and $5.4 \mathrm{~kW} \mathrm{~m}^{-1}$ (pellet power) whilst at low power, this causes a compressive stress of $-42.6 \mathrm{MPa}$ at the end of the transient.

Previous work has shown a population of incipient cracks in cladding material surrounding fuel pellets $[10,50$, 51]. This suggests that the initiation phase is less important than the growth phase and modelling work is therefore focusing upon determining the conditions under which these cracks will grow rather than understanding their propensity to initiate.

In this work, the creep strain at the $\mathrm{CBC}$ tip has been taken as the most applicable indicator of PCMI since $\mathrm{CBCs}$ are thought to grow through creep ductility exhaustion. Comparing the average $\mathrm{CBC}$ length measured in PIE to the total creep strain accrued in these simulations shows a similar pattern (Fig. 15). The maximum average $\mathrm{CBC}$ depth is in element 6 , as is the maximum total creep strain accrued. In addition, comparing the creep strain accrued during the up-rate and the pre-transient hold, the hold caused the most creep strain and the up-rate has a relatively small effect; the exception was element 8 , the hottest element. These results are relatively good, considering that a simple reduction of power to $70 \%$ has been compared to the whole of a fuel elements life. Considering the differences between the $\mathrm{CBC}$ depth and the creep strain predicted, the higher crack depth in elements 4 and 5 might be due to control rod movement. The higher CBC depth in element 8 might be due to either the effect of carbon deposition on fuel pins in higher elements or incomplete fuel densification. Although no CBCs above the threshold depth of $5 \mu \mathrm{m}$ have been seen in elements 1 and 2 , creep strains are predicted by this model.

Fig. 12 reveals that in all elements except element 8 , the creep rate at the $\mathrm{CBC}$ tip following the transient is greater than prior to it. This is the result of additional outward radial displacement of the pellet due to the irradiation creep in the pellet. In elements 2-5, more creep is accrued at the CBC tip than had the transient not taken place. In elements 6 and 7, the transient reduced the total creep strain accrued at the CBC tip as the period of reduced power resulted in less fuel swelling. In all cases except element 7, more creep strain was accrued at the $\mathrm{CBC}$ tip during the up-rate than during the down-rate.

Geometric factors relating the $\mathrm{CBC}$ geometry have been shown to be less important than those relating to pellet crack geometry. Altering the sliver thickness and the shape of the circumferential crack forming the sliver had very little effect upon the creep strain accrued at the $\mathrm{CBC}$ tip. Once the clad damage model is validated against $\mathrm{CBC}$ growth data, the model will be able to investigate a wide range of conditions and an idealised sliver-pellet 
formation used with confidence. Plotting the creep strain against $\mathrm{CBC}$ depth showed that for depths between 2.5 and $10 \mu \mathrm{m}$ (Fig. 13), the creep strain accrued at the $\mathrm{CBC}$ tip was proportional to the $\mathrm{CBC}$ depth, suggesting that the crack growth rate is likely to be proportional to the $\mathrm{CBC}$ depth over this range. It can therefore be expected that as $\mathrm{CBCs}$ grow, their growth will accelerate.

It should be remembered that the current model considers cladding bonded to a sliver containing ladder cracks. Whilst some bonding or mechanical interaction is routinely observed in elements 3 to 8 , with some bonding in element 2, ladder cracking is not always observed in PIE and their observation is generally seen as the exception rather than the rule [31]. One explanation for this is that due to their fine hairline nature, they close during the reduction in power, final shut-down and storage in ponds for many months. Another explanation is that ladder cracks are genuinely rare. Fig. 14a shows that very high tensile hoop stresses (424 MPa) were observed in the sliver as a result of thermal expansion during the initial rise to power. These could be sufficient to introduce the ladder cracks given a fuel fracture stress in the range of 50 -250 MPa, with a value of $125 \mathrm{MPa}$ considered typical [58-61]. In addition, both modelling and experimental work has shown a greater concentration of cracks on the outer surface of the pellet compared to the inner surface in AGR fuel [62] and a number of radial cracks on the outer surface of PWR fuel [63].

Finally, the model reported here does not allow ladder crack closure. Since compressive stresses of order $5 \mathrm{MPa}$ were observed during the low-power hold, it is likely that the ladder cracks will close and the results generated might not be valid under these conditions. Future work will therefore also focus upon modelling the closure of these cracks as this is likely to have a significant influence, as demonstrated in Figs. 14a-b. During the downrate, the hoop stress in the sliver with no ladder cracks became strongly compressive, causing an increase in the creep strain at the $\mathrm{CBC}$ tip of $7.8 \%$. During the up-rate and holds at full power, the hoop stress in the sliver became strongly tensile and so the results of the model in which ladder cracks are modelled would be more appropriate. The result of modelling ladder crack closure is therefore likely to be similar to the superposition of the results of the model with no ladder cracks during the down-rate and hold at low power upon those of the model with open ladder cracks during the rest of the simulation.

\section{Conclusions}

The model presented here is able to predict the general pattern of the average depth of CBCs measured in transverse sections of AGR fuel with axial position in the core. The following conclusions about the behaviour of bonded cladding under the operating conditions considered can be made:

- Small differences in the radial displacement of the pellet outer surface had a significant effect upon the hoop stress in the cladding and the creep strain at the CBC tip.

- Holds at full power were observed to account for the majority of the creep strain predicted at a CBC tip in all elements except element 8 . If account is taken of ladder crack closure, it is possible that the down-rate and hold at low power would have more significance. 
- Irradiation creep in the inner regions of the fuel pellets caused the outer surface of the pellet to advance more into the cladding during the up-rate than it receded during the down-rate. Colder, high power fuel elements showed an increased creep strain at the $\mathrm{CBC}$ tip due to the transient as a result of this.

- Hotter, high power fuel elements saw increased thermal creep in bulk cladding during low power operation. This caused a post-transient stress reversal and alleviated the effect of the additional pellet displacement.

- Generally, it was found that adjusting geometric parameters related to fuel cracking had little effect upon the magnitude of pellet-clad interaction. This includes changing the ratio of the sliver thickness close to and away from the pellet crack. The effect of the shape of individual pellet fragments is therefore likely to be small.

Whilst AGR fuel has been investigated here, it is anticipated that techniques employed will also be applicable to bonded LWR fuel.

\section{Acknowledgments}

Thomas Haynes would like to thank technical support from the Nuclear Technology Branch of EDF Energy and staff at Hinkley Point B and Heysham 1 power stations, as well as financial support from both EDF Energy and the Engineering and Physical Sciences Research Council. Dr Mark Wenman would like to thank financial support from EDF Energy. Mr Haynes and Dr Wenman would like to thank Dr Susan Morgan and John Thompson from National Nuclear Laboratory's Windscale Laboratories for their demonstration and discussion of PIE techniques and results.

\section{List of Figures}

1 A summary of the features of interest in AGR PCI: large radial cracks from the centre of the annular fuel pellet to the cladding surface; a strong bond between the cladding and pellet; circumferential cracks some distance from the fuel-cladding surface, leaving a sliver of fuel attached to the cladding; radial 'ladder cracking' in this adherent sliver; and, the deposition of a carbonaceous deposit on the cladding. Micrographs courtesy of EDF Energy Generation.

2 The three components of a fuel pin segment used in the model, together with their associated boundary conditions and thermal loads. This figure shows the situation before creep down; following this, the cladding and sliver bond and the pellet and sliver are free to separate. Insert is schematic and not to scale; only the outer region of the pellet is modelled.

3 The maximum principal stress under steady state operation. The lines ' 1 ' and ' 2 ' and points A-D are used in other figures.

4 The linear rating and coolant temperature in each fuel element. Elements are numbered from the bottom to the top of the reactor.

$5 \quad$ Fuel-clad gap and temperature drop during early life in element 5. During this period, the detachable sliver and bulk pellet are joined and the gap is open between the cladding and sliver.

6 The variation of the time for clad-fuel contact and maximum gap element with element number. Elements are numbered from the bottom to the top of the reactor. 

element 5 .

8 The opening of the pellet crack (point C, Fig. 3); and the radial motion of the pellet (point D Fig. 3) during the test transient for element 5. The schematic inserts show the axial motion of the pellet during the transient; pellet deformation is magnified by a factor of 100 .

9a-b The thermal strain in bulk cladding (point A, Fig. 3) and the sliver (point B, Fig. 3) of element 5 during the down-rate (a) and up-rate (b), together with the total and elastic hoop strain in the cladding. All strains and times are the difference between the current value and that at the start of the test transient.

10 The hoop stress in bulk cladding (point A, Fig. 3) each fuel element at the end of the power up-rate (730-740h).

11 The radial profile of the hoop stress (a) in the bulk cladding (line 1, Fig. 3) and ahead of a radial fuel crack (line 2, Fig. 3) with and without a $\mathrm{CBC}$ for element 5 at the end of the up-rate. The insets show contour-plots of the hoop stress, von Mises stress and equivalent creep strain for the model with a CBC introduced (units MPa and absolute strain).

12 The creep strain accrued at the CBC tip for each element during each stage of the test transient together with the creep strain accrued in the absence of low power operation.

13 A summary of the sensitivity of the equivalent creep strain accrued during the up-rate to a number of assumptions made in the model. In each case, the independent variable is the ratio of the perturbed to default value; the sliver curvature ratio is the ratio of the sliver thickness away from the CBC (base of line 1, Fig. 3) to that close to the CBC (point C, Fig. 3).

14a-b The hoop stress in the sliver (a) and the creep strain at the CBC tip (b) for models in which ladder cracks are and are not introduced.

15 The average CBC depth measured compared to the total creep strain predicted. Elements are numbered from the bottom to the top of the core.

\section{List of Tables}

$1 \quad$ Parameters used \& definition of each step

2 The constants used in the correlation (equation 12) for $\mathrm{UO}_{2}$ thermal conductivity 


\section{References}

[1] B. Cox, Journal of Nuclear Materials, 172 (1990) 249-292.

[2] S.K. Yagnik, D.J. Sunderland, B.C. Cheng, Pellet-Clad Interaction in Water Reactor Fuels Transactions, Aix-en-Provence, (2004) 63-77.

[3] B. Michel, J. Sercombe, G. Thouvenin, Nuclear Engineering and Design, 238 (2008) 1612-1628.

[4] C. Bernaudat, Nuclear Engineering and Design, 156 (1995) 373-381.

[5] J. Brochard, F. Bentejac, N. Hourdequin, S. Seror, C. Verdeau, O. Fandeur, S. Lansiart, P. Verpeaux, Transactions, SMiRT 16, Washington DC, 1314 (2010).

[6] J.C. Wood, IAEA Specialists Meeting on Power Ramping and Power Cycling of Water Reactor Fuels; Arles, France, 17 (1979) 1-8.

[7] P. Van Uffelen, K. Lassmannm, A. Schubert, J. Van de Laar, C. Gyori, D. Elenkov, B. Hatala, PelletClad Interaction in Water Reactor Fuels Transactions, Aix-en-Provence, (2004) 53-62.

[8] A.V. Smirnov, B.A. Kanashov, D.V. Markov, V.A. Ovchinikov, V.S. Polenok, A.A. Ivashchenko, Pellet-Clad Interaction in Water Reactor Fuels Transactions, Aix-en-Provence, (2004) 231-240.

[9] G.G. Bond, A.G. Uglow, Nuclear Engineering and Design, 56 (1980) 135-141.

[10] J.H. Shea, G.A. Gates, S.L. Brown, P.A. Tempest, TopFuel '97 Transactions, 5 (1997) 176-183.

[11] J.H. Gittus, D.A. Howl, H. Hughes, Nuclear Applications \& Technology, 9 (1970) 40-46.

[12] J.S. Armijo, Z. Abdullahi, United States Nuclear Regulatory Commission, (2009).

[13] B. Michel, J. Sercombe, G. Thouvenin, R. Chatelet, Engineering Fracture Mechanics, 75 (2008) 3581-3598.

[14] R. Kallstrom, J.K.H. Karlsson, J. Johansson, M. Levy, J. Minay, M. Barker, M. Gonzales, TopFuel 2012 Transactions, (2012) 104-109.

[15] S. Morgan, A.M. Gate, J.F.W. Thompson, M. Barker, R. Talling, TopFuel 2012 Transactions, (2012) 515-519.

[16] K.-F. Nilsson, O. Martin, C. Chenel-Ramos, J. Mendes, Nuclear Engineering and Design, 241 (2011) 445-458.

[17] C. Mougel, B. Verhaeghe, C. Verdeau, S. Lansiart, S. Beguin, B. Julien, Pellet-Clad Interaction in Water Reactor Fuels Transactions, Aix-en-Provence, (2004) 333-345.

[18] W. Wiesenack, T. Tverberg, Pellet-Clad Interaction in Water Reactor Fuels Transactions, Aix-enProvence, (2004) 321-332.

[19] Y.M. Kim, Y.S. Yang, C.B. Lee, D.H. Kim, Y.H. Jung, Pellet-Clad Interaction in Water Reactor Fuels Transactions, Aix-en-Provence, (2004) 425-437.

[20] S.P. Walker, A. Yu, R.T. Fenner, Nuclear Engineering and Design, 138 (1992) 403-408.

[21] J.H. Shea, EDF Energy, (2012).

[22] N. Marchal, C. Campos, C. Garnier, Computational Materials Science, 45 (2009) 821-826.

[23] J. Sercombe, I. Aubrun, C. Nonon, Nuclear Engineering and Design, 242 (2012) 164-181.

[24] P. Rudling, R. Adamson, B. Cox, F. Garzarolli, A. Strasser, Nuclear engineering and Technology, 40 (2008) 1-8.

[25] K. Nogita, K. Une, Nuclear Science and Technology, 34 (1997) 679-686.

[26] M. Suzuki, H. Saitou, T. Fuketa, Nuclear Science and Technology, 43 (2006) 1097-1104.

[27] R.E. Pendlebury, Nuclear Electric, TD/SID/MEM/0274 (1992).

[28] T. Helfer, P. Garcia, J.M. Ricaud, D. Pancq, C. Struzik, Pellet-Clad Interaction in Water Reactor Fuels Transactions, Aix-en-Provence, (2004) 367-377.

[29] I.K. Dickson, G. Roberts, Nuclear Engineering and Design, 56 (1980) 273-277.

[30] R.L. Williamson, J.D. Hales, S.R. Novascone, M.R. Tonks, D.R. Gaston, C.J. Permann, D. Andrs, R.C. Martineau, Journal of Nuclear Materials, 423 (2012) 149-163.

[31] S. Morgan, Personal Communication (2015).

[32] M.V. Frank, W.E. Kastenburg, Nuclear Engineering and Design, 1980 (1980) 49-59.

[33] A. Soba, A. Denis, Journal of Nuclear Materials, 374 (2008) 32-43.

[34] J.C. Wood, Journal of Nuclear Materials, 45 (1972) 105-122.

[35] I. Schuster, C. Lemaignan, Journal of Nuclear Materials, 189 (1992) 157-166. 
[36] P.S. Sidky, Journal of Nuclear Materials, 256 (1998) 1-17.

[37] D.J. Sunderland, Nuclear Science and Technology Interaction Program (NSTIP), ORNL, (2011).

[38] R.L. Williamson, Journal of Nuclear Materials, 415 (2011) 74-83.

[39] R. Mella, M.R. Wenman, Journal of Nuclear Materials, 437 (2013) 154-165.

[40] J.H. Shea, EDF Energy, E/REP/BBFB/0039/GEN/07 (2009).

[41] G. Dieter, McGraw-Hill, New York, (1988).

[42] A. Yu, S.P. Walker, R.T. Fenner, Nuclear Engineering and Design, 121 (1990) 53-58.

[43] J.M. Gatt, J. Sercombe, I. Aubrun, J.C. Menard, ECF 19 Transactions, Kazan, (2012).

[44] P. Brohan, J.H. Shea, Nuclear Electric, AGR/FPWG/P(90)1641 (1998).

[45] J. Sercombe, R. Masson, T. Helfer, Nuclear Engineering and Design, 260 (2013) 175-187.

[46] R.C. Ecob, R.C. Lobb, C.L. Kohler, Journal of Materials Science, 22 (1987) 2867-2880.

[47] J.H. Gittus, Nuclear Engineering And Design, 18 (1972) 69-82.

[48] J.G. Gravenor, J. Douglas, Journal of Nuclear Materials, 158 (1988) 87-95.

[49] J.H. Shea, Nuclear Electric, EPD/AGR/REP/0188/96 (1997).

[50] G. Lysell, K. Kitano, D. Schrire, J.E. Lindback, Pellet-Clad Interaction in Water Reactor Fuels Transactions, Aisx-en-Provence, (2004) 273-278.

[51] K. Kitano, C. Losin, J. Arborelius, M. Limbäck, Water Reactor Fuel Performance Meeting

(TopFuel) 2005 Transactions, (2005) 268-275.

[52] R.C. Ecob, R.A. Gomme, British Energy, FPWG/P(89)924 (2000).

[53] R.A. Gomme, D.G. Martin, J.R. Matthews, Nuclear Electric, AGR/FPWG/P(90)1668/A (1990).

[54] B.D. Clay, Central Electricity Generating Board, AGR/FPWG/P(87)1131 (1987).

[55] K. Hashimoto, N. Matsunaga, A. Nagashima, K. Mito, International Journal of Thermophysics, 13 (1992) 211-221.

[56] C. Baker, J.W. Tyler, Nuclear Electric, TD/FCB/MEM/0001 (1990).

[57] N. Beatham, Windscale Nuclear Power Development Laboratories, AGR/FPWG/P(86)896 (1986).

[58] A.G. Evans, R.W. Davidge, Journal of Nuclear Materials, 33 (1969) 249-260.

[59] L.J. Siefken, E.W. Coryell, E.A. Harvego, J.K. Hohorst, Idaho National Engineering and Environmental Laboratory, (2001).

[60] J.T.A. Roberts, J. Ueda, Journal of the American Ceramic Society, 55 (1972) 118-124.

[61] F.P. Knudsen, H.S. Parker, M.D. Burdick, Journal of the American Ceramic Society, 43 (1960).

[62] R. Mella, M.R. Wenman, In Review : Journal of Nuclear Materials, (2015).

[63] H. Huang, B. Spencer, J. Hales, Nuclear Engineering and Design, 278 (2014) 515-528. 


\author{
JNM-D-15-00169 \\ Responses to reviewers' comments
}

\title{
Reviewer's Comment 1
}

"As this is a modelling paper, I was disturbed not to see any equations, except for certain parameters in table 2. I believe (but am unsure) that you are solving infinitesimal elasticity in three domains. I am unsure since I don't seen any equations though. What are the PDEs? How (explicitly in mathematical notation) is creep implemented? Are you solving for temperature too? Contact?"

Please see the new sections 2.2-2.5. Section 2.2 gives a summary of the finite element approach; section 2.3 details the materials models used; section 2.4 the thermal properties and 2.5 the interactions between parts, including contact.

The re-written sections now include 12 equations. The PDEs solved are detailed in the body of the text: "For a coupled temperature-displacement simulation, the partial differential equations are the differential forms of Newton's second law and Hook's law together with Poisson's equation. The material properties are a function of burn-up, stress and temperature."

"On the same point, table 2 is incomplete. Parameters are defined (in some cases multiple times) but their values are absent. In some cases they are enigmatic as "Tabulated: 30 values in the range $00 \mathrm{C}$ to $25000 \mathrm{C}$." with no reference. They could be anything. Whereas the purpose of this documentation is to be able to reproduce your results, I wouldn't know where to start."

The previous table 2, which dealt with the material models has been removed and the equations used incorporated into a re-written section 2.3. We have given the functional form of all of the relations and their source within the body of the text. Whilst we regard this document as being primarily academic work, many of the exact values of constants used in the material properties result from propriety industrial research owned by EDF Energy and carried out by the former Central Electricity Generating Board, Nuclear Electric, United Kingdom Atomic Energy Authority as well as other organizations. As such, they are likely to be subject to export controls by the UK Government and hence we are not permitted to include them. However the exact values are less important than the methods we describe and therefore hope to be adequate.

\section{Reviewer's Comment 2}

"The readability and logic of the arguments is difficult to follow due to a zealous use of semicolons (an average of almost 8 per page of text). I found myself frequently rereading sentences in order to understand the meaning. In most cases, I feel breaking these sentences would result in much more readable text. I have marked a (partial) selection of these." 
The number of semicolons in the body of the text has been substantially reduced.

\section{Reviewer's Comment 3}

"The introduction is impressive and provides a deep discussion of the current state of modelling but the final paragraph, where the current work is introduced, falls flat. I suggest you bolster this paragraph by including a preview of what specifically you are going to study and hinting at some results. Of all the models previously discussed, what are you doing differently? Or is yours the same (for now) but building to something else? Where does your model sit with respect to the other models and what phenomena are you considering?"

The paragraph has been extended to summarize how the model presented differs from previous models: "The model differs from previous FE models of PCMI in that the stress concentration ahead of cracks in the cladding has been modelled and the effect of a sliver of fuel bonded to the cladding considered. This work found that modelling the hairline ladder cracks in the sliver of fuel substantially reduces the creep strain accrued ahead of the CBC tip and therefore the propensity of the clad bore crack to propagate. It is noted that the geometric shape of the crack fragments had little effect upon the extent of PCMI."

\section{Reviewer's Comment 4}

"Please remove the italic from Imu when it is part of a unit."

The italic has been removed.

\section{Reviewer's Comment 5}

"Some description of the computational expense / requirement of solving this model would be helpful."

A new paragraph has been included which states: "The simulations were carried out on a single core of a $3.50 \mathrm{GHz}$ Intel Xeon E5-2637 processor running on a computer with $64 \mathrm{MB}$ of RAM. Parallelisation was not used due to the relatively poor parallelisation capability of Abaqus 6.11. The simulations took between 5.6 and $18.0 \mathrm{~h}$ to run and created between 31 and 73 GB of data."

\section{Reviewer's Comment 6}

"In section 3.2 (the second section so marked), you suddenly mention 'a whole pellet fuel model under development'. Is the reader to understand that this is a different model from the one described in the current work?"

The sections have been renumbered and the figure is now described as being schematic since the deformations shown are not to scale. The 'whole pellet' mode is being developed to better understand pellet relocation and will be reported at the TopFuel 2015 conference in Zurich this September and is not needed to appreciate this work. 


\section{Editor's Comment}

"I would request to show some basic equations used for the computation, even if a commercial (well-known) software package is used."

Please see our answer to reviewer comment no. 1. 


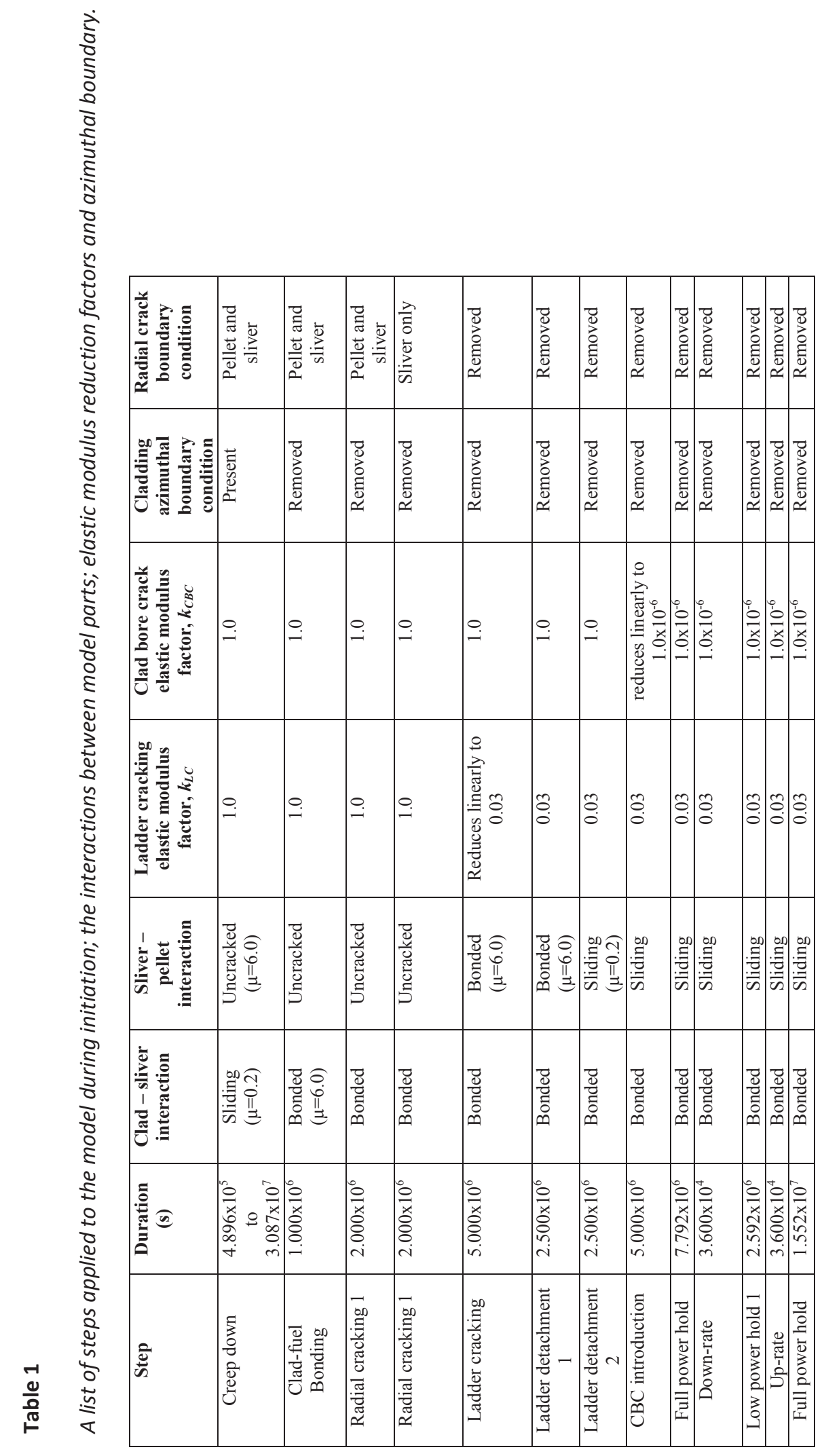


Table 2

The constants used in the correlation (equation 11) for $\mathrm{UO}_{2}$ thermal conductivity

\begin{tabular}{|c|c|}
\hline Constant & Value \\
\hline$\lambda_{\mathrm{T} 0}$ & 9.95308 \\
\hline$\lambda_{\mathrm{T} 1}$ & $-1.07995 \times 10^{-2}$ \\
\hline$\lambda_{\mathrm{T} 2}$ & $4.28489 \times 10^{-6}$ \\
\hline$\lambda_{\mathrm{B} 0}$ & 1.10435 \\
\hline$\lambda_{\mathrm{B} 1}$ & $-1.61978 \times 10^{-2}$ \\
\hline$\lambda_{\mathrm{B} 2}$ & $3.47946 \times 10^{-4}$ \\
\hline
\end{tabular}




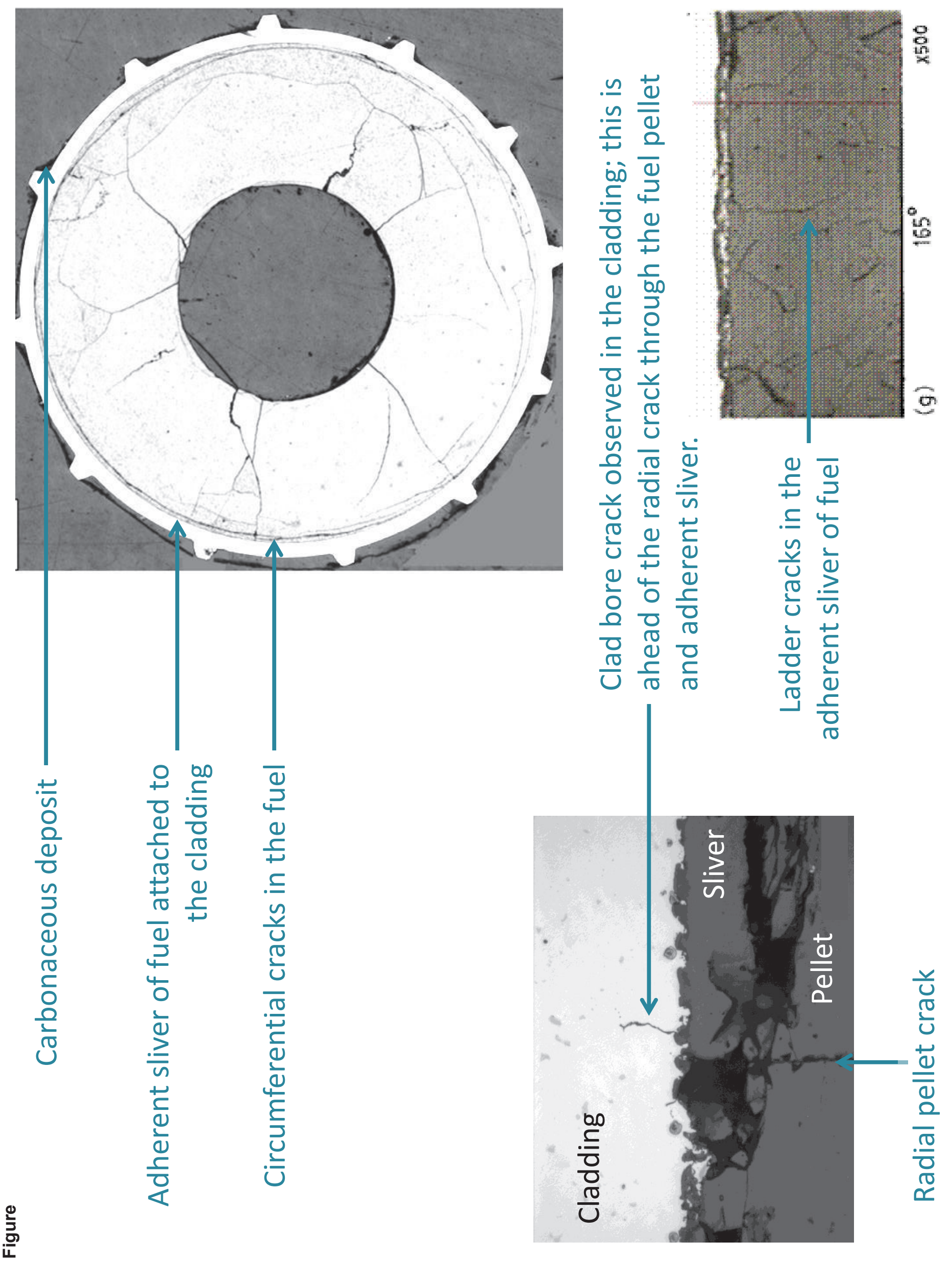




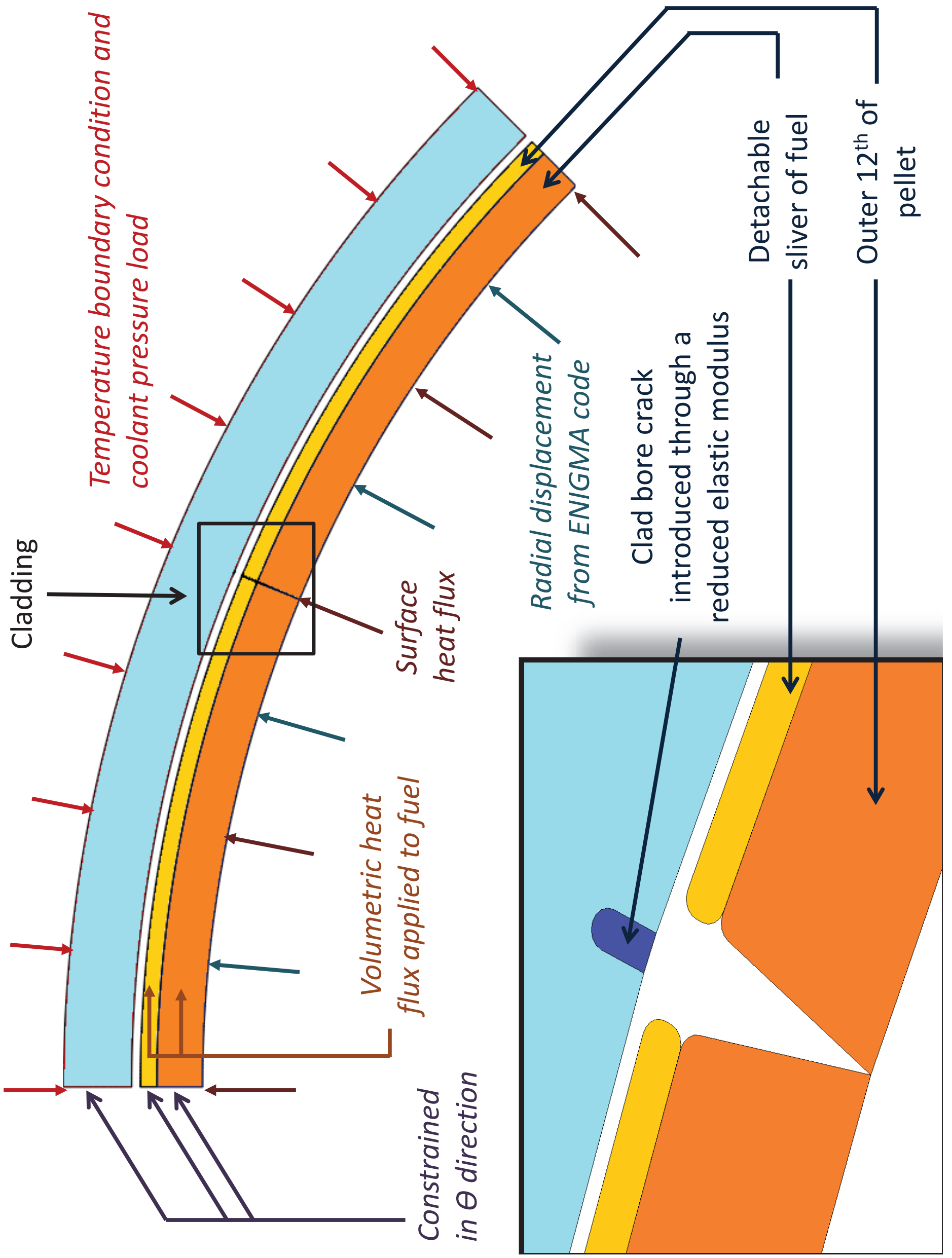




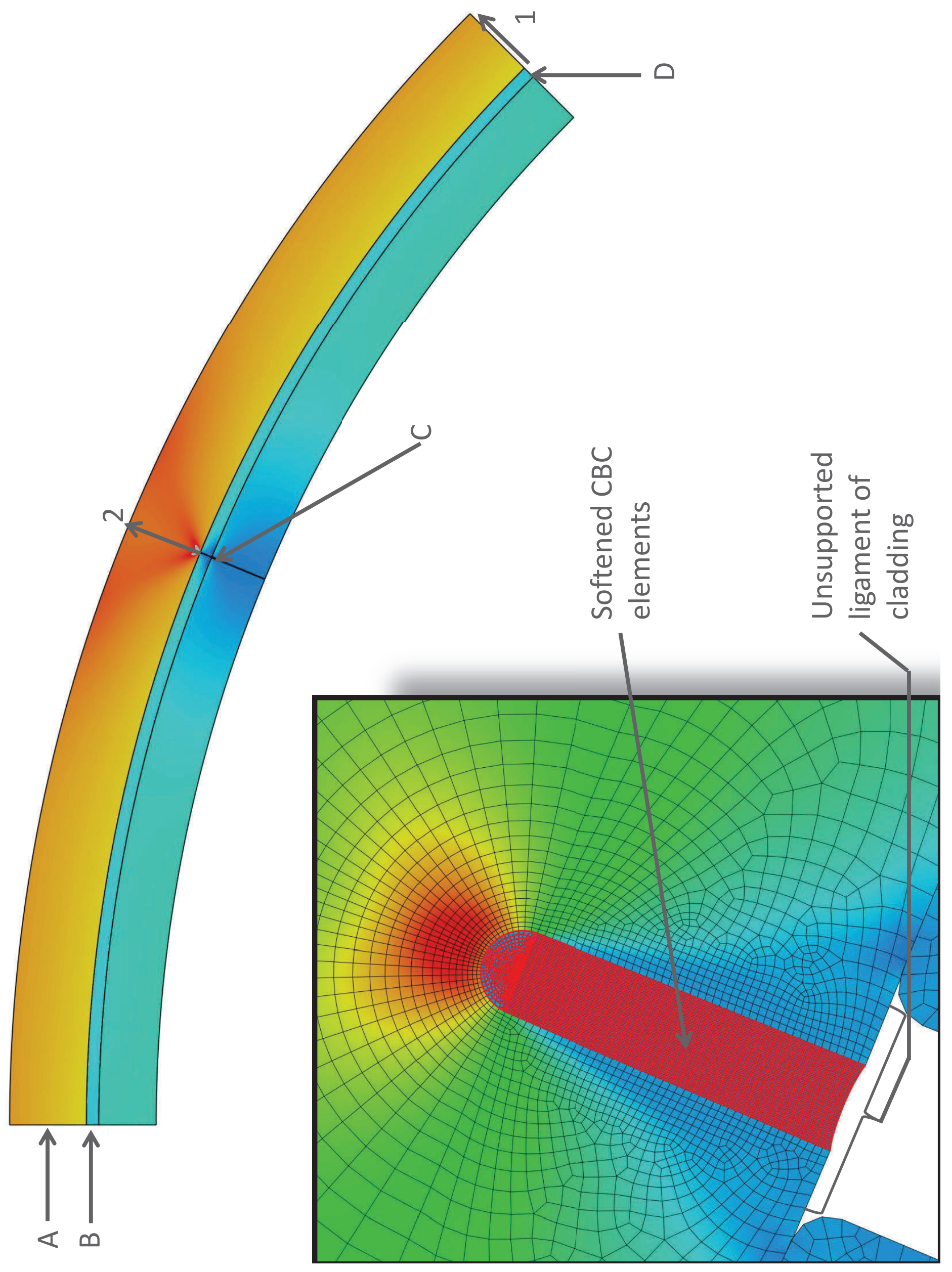




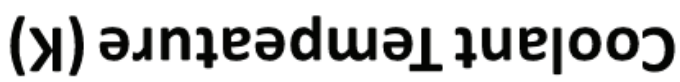

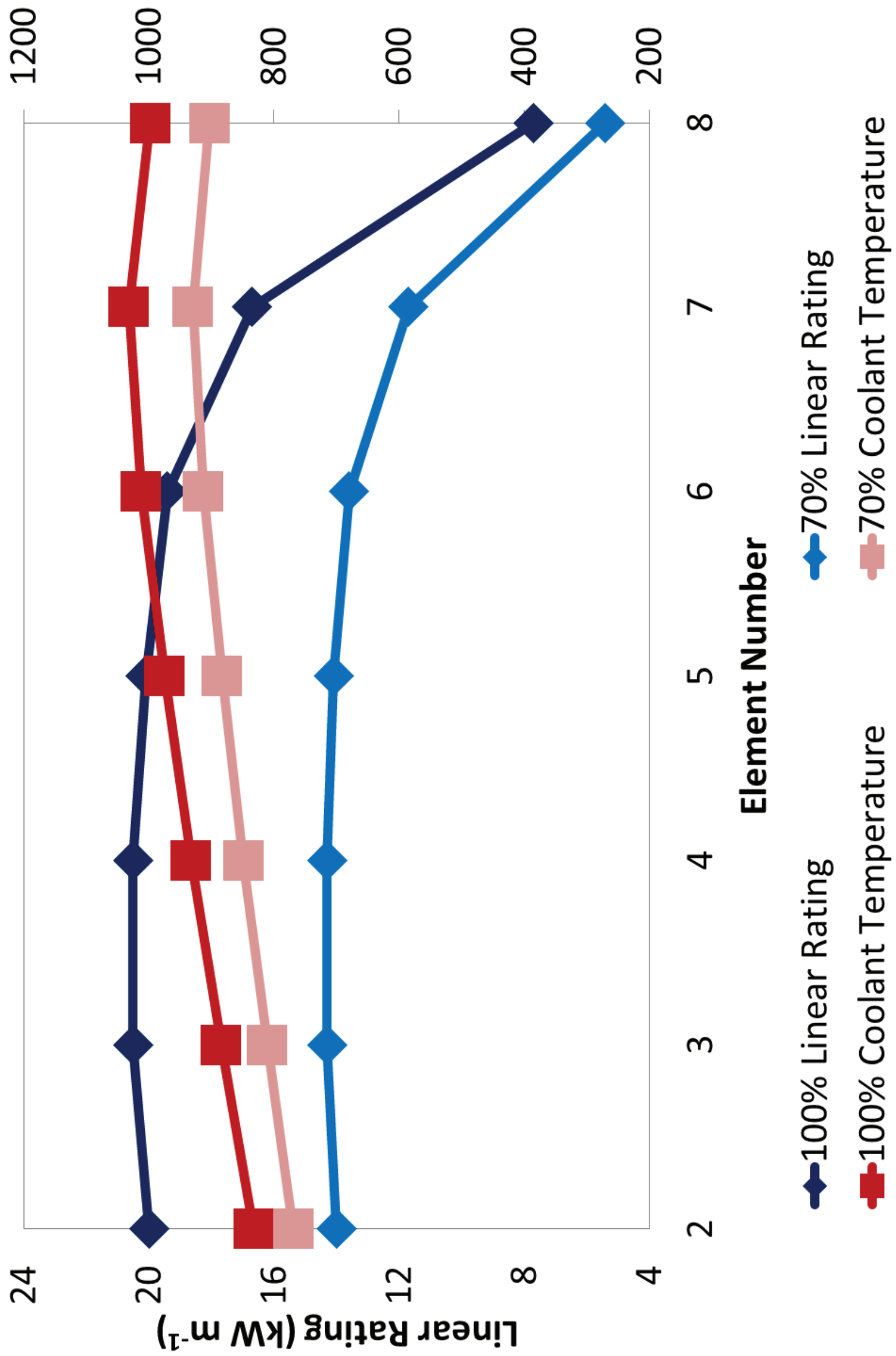




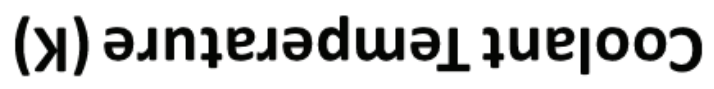
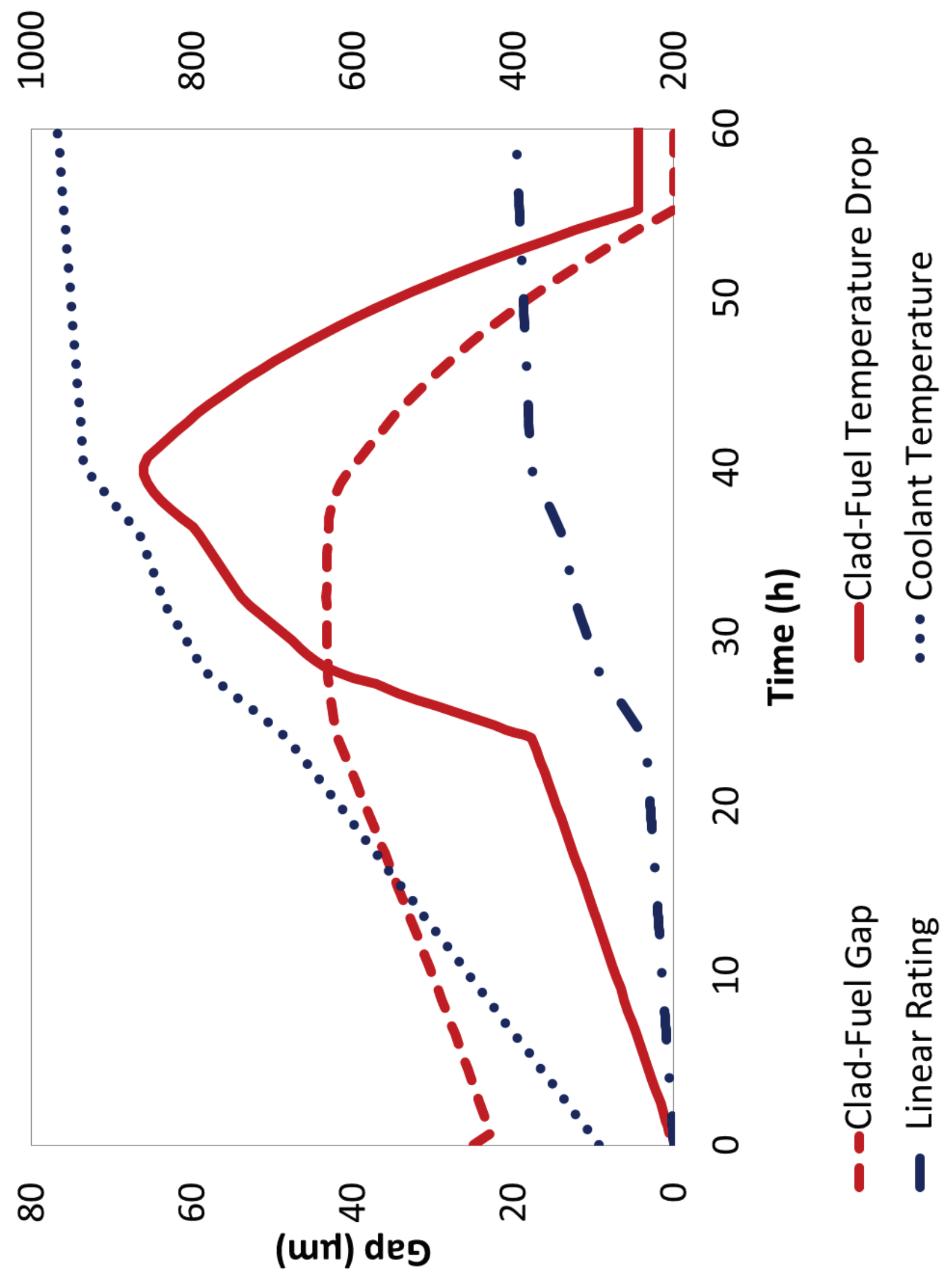

(x) dosa әдnfeesəduə।

(โ-U My) 8u!fey deəu! 


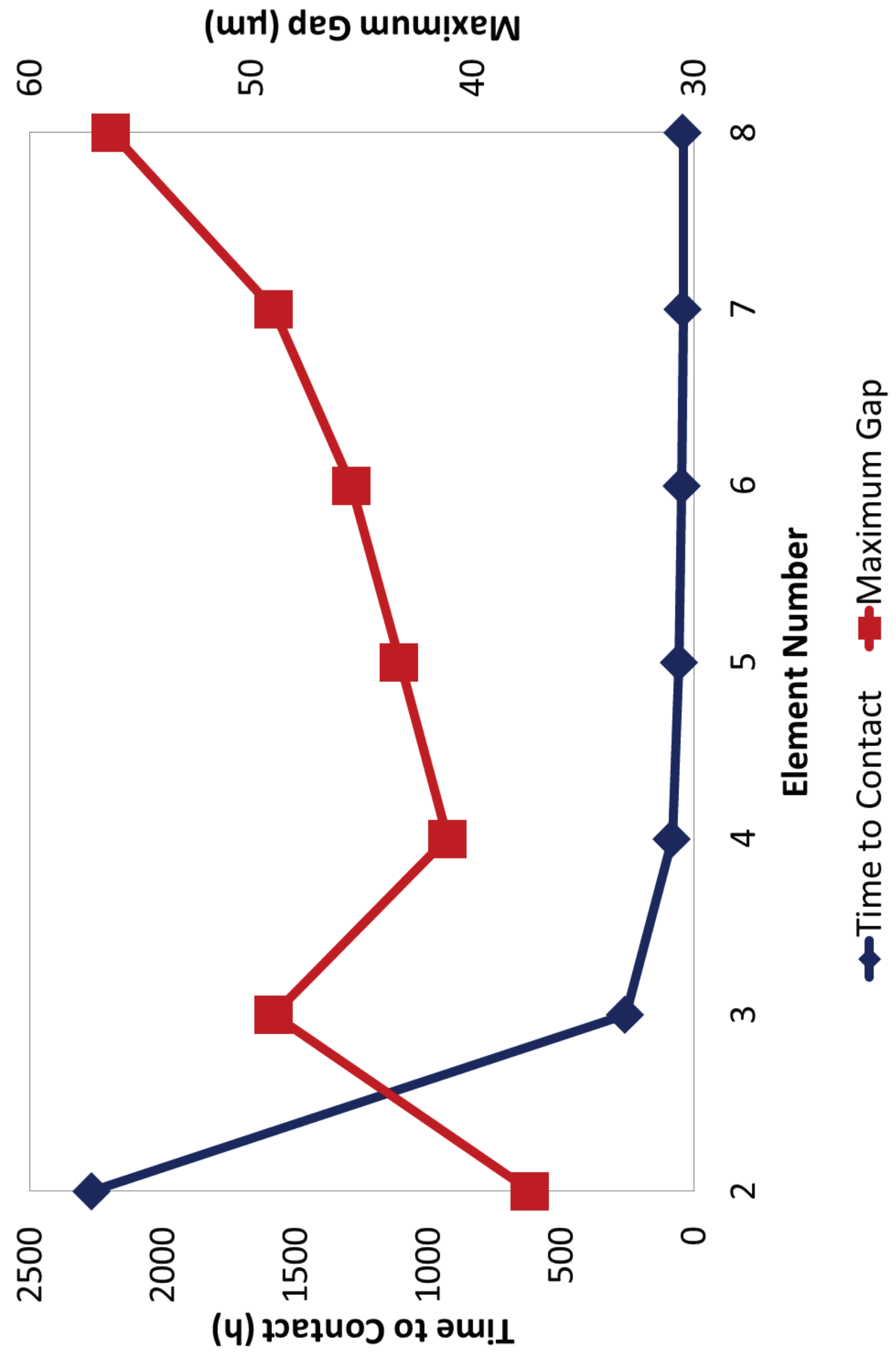


(\%) 8u!ppe|ว u! u!̣גzs dəəגว

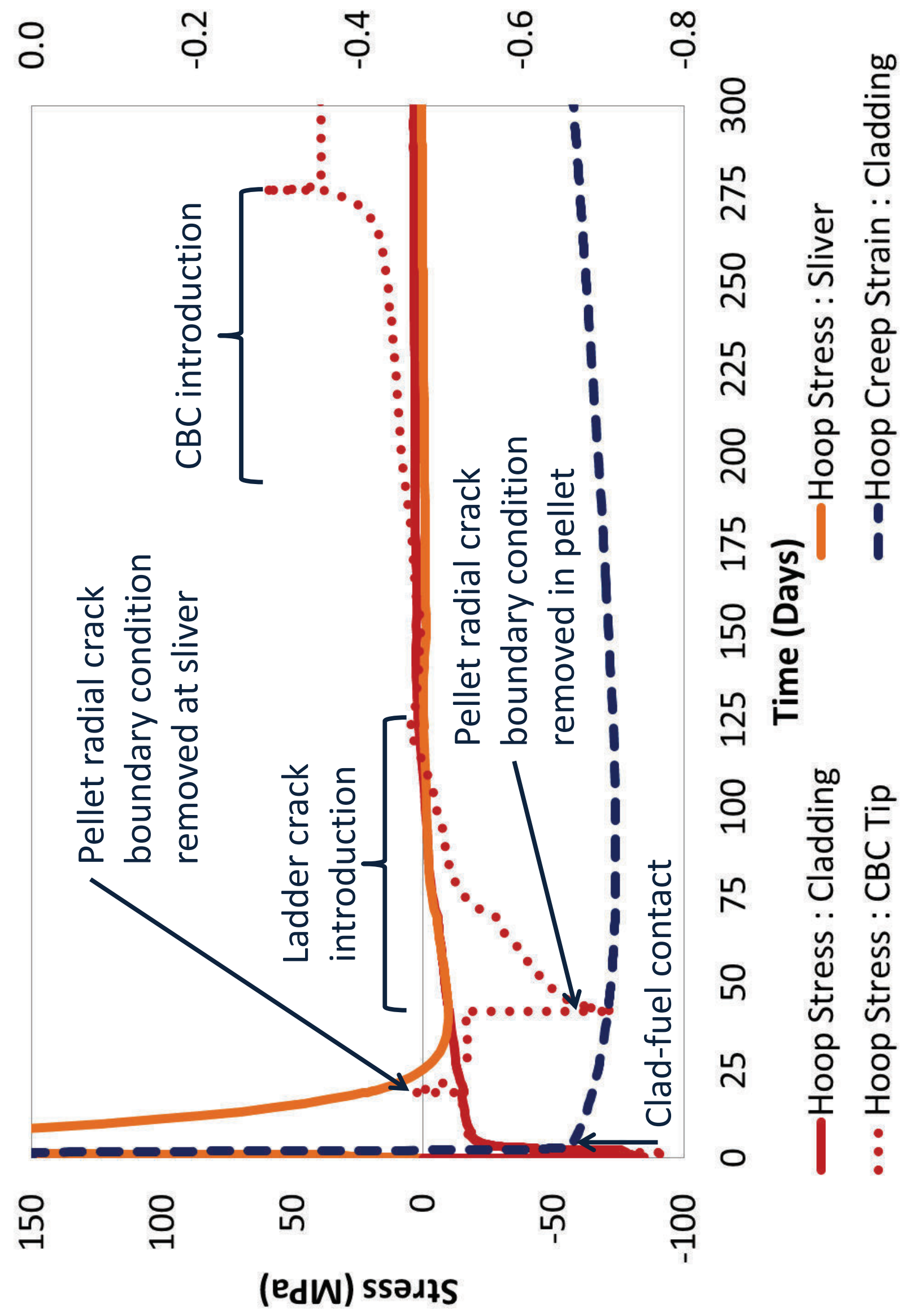



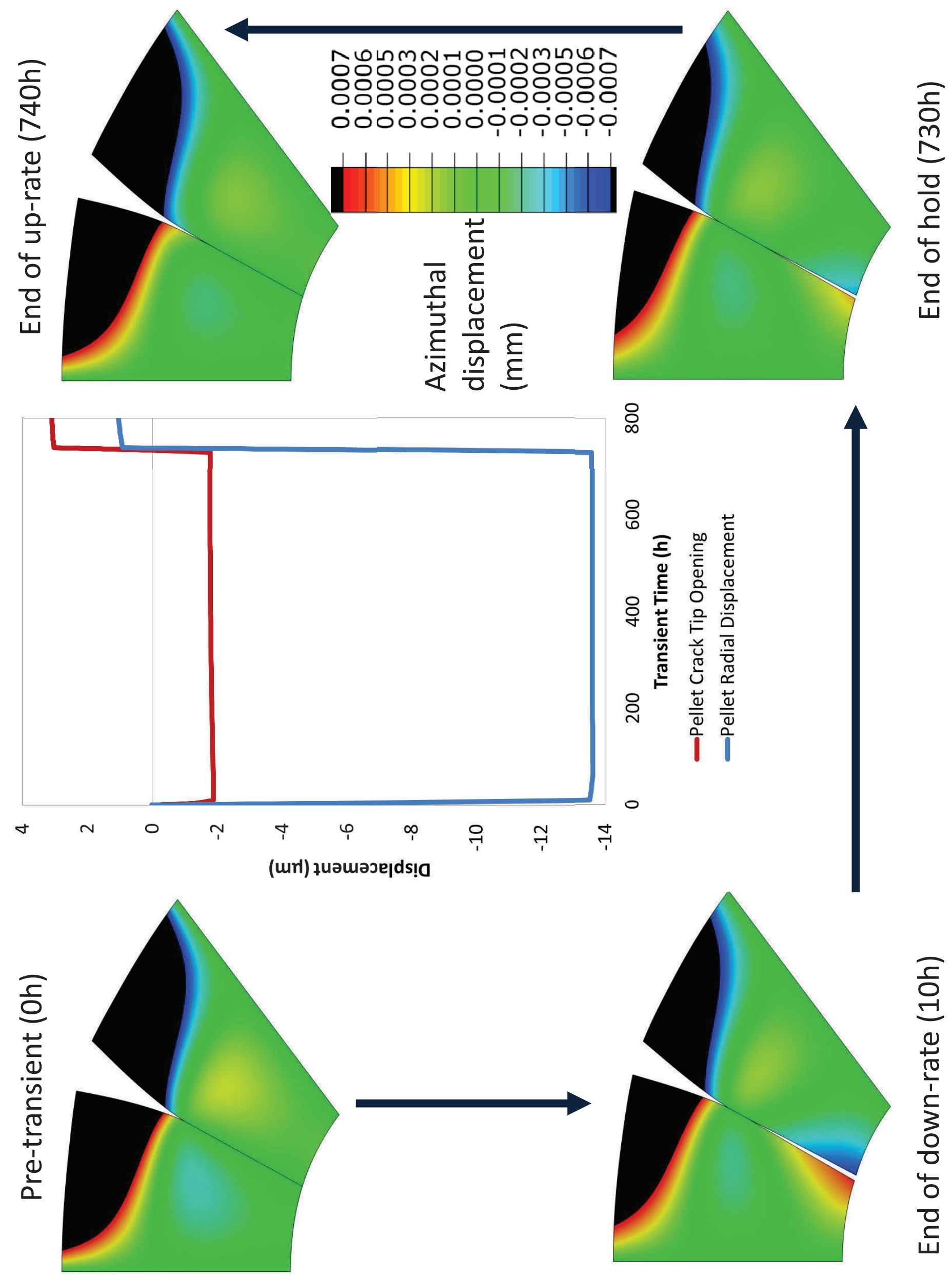

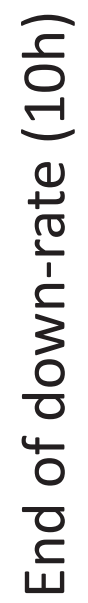




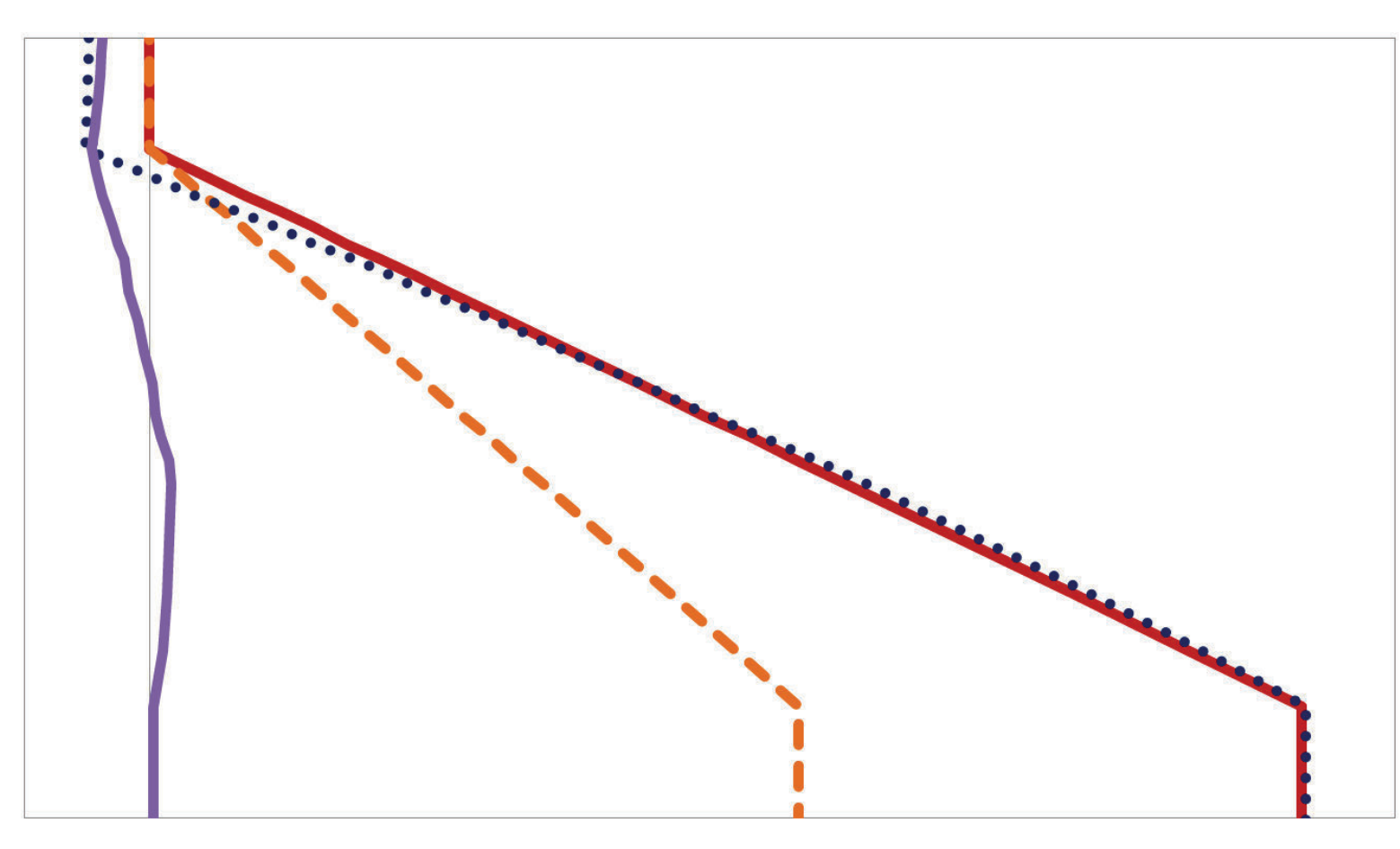

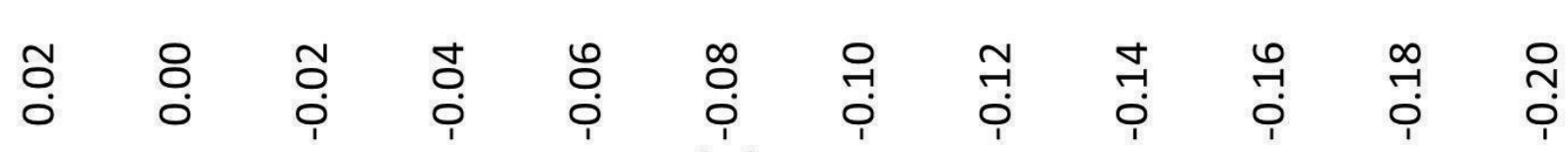

Q

(\%) u!exts

ঙัก

요 है

$\stackrel{\infty}{\sim} \cong \stackrel{\oplus}{\models}$

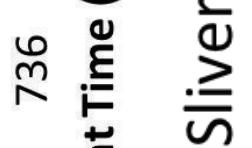

年 $\frac{\mathrm{d}}{\mathrm{W}}$

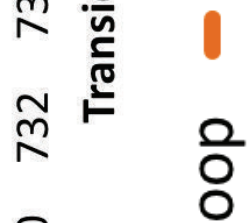

욧 우

$\stackrel{\sim}{N}$

N

ธี

ర

$\frac{\pi}{0}$

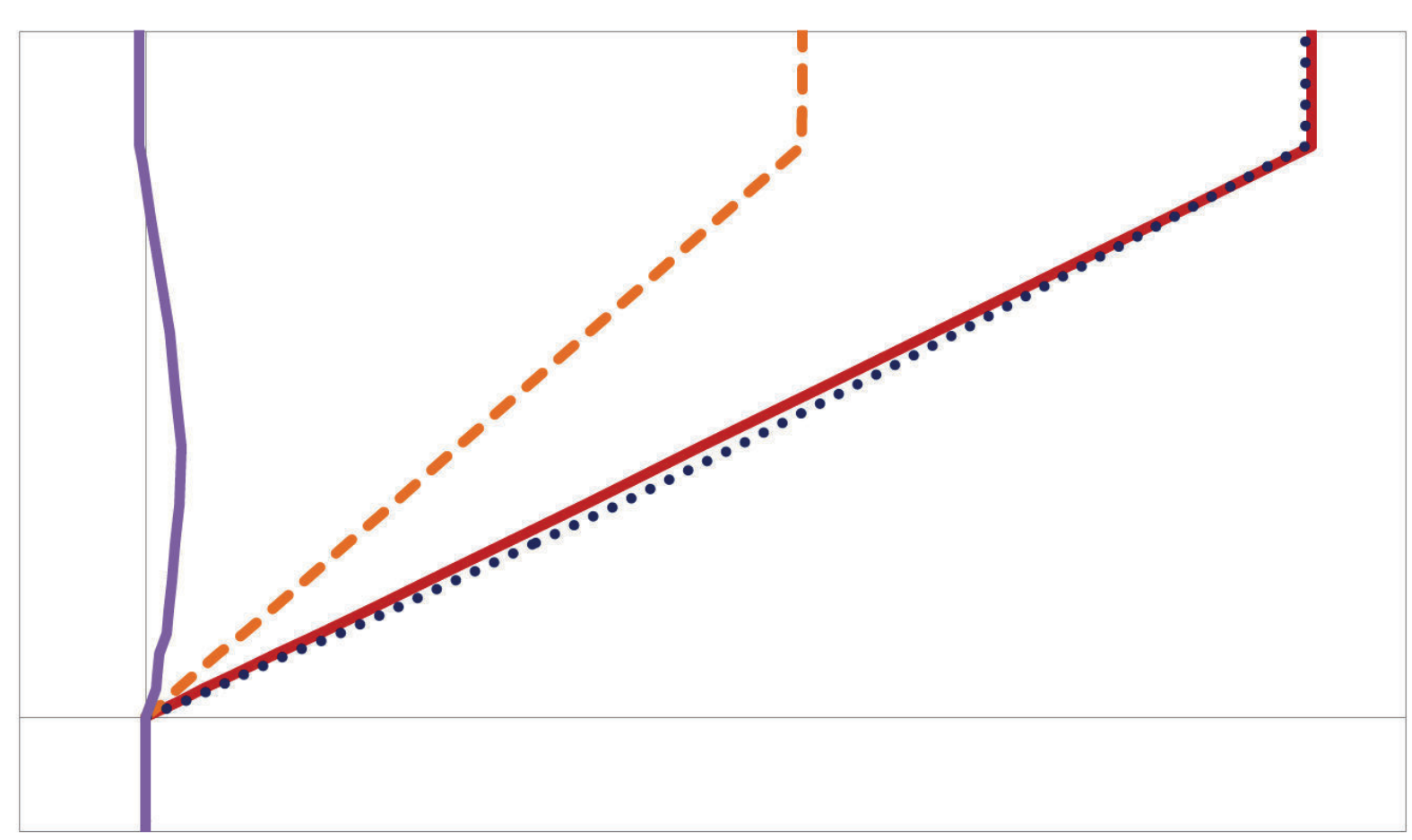

ㄱำ

요

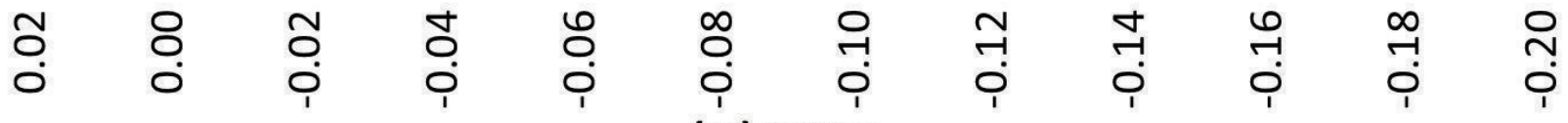




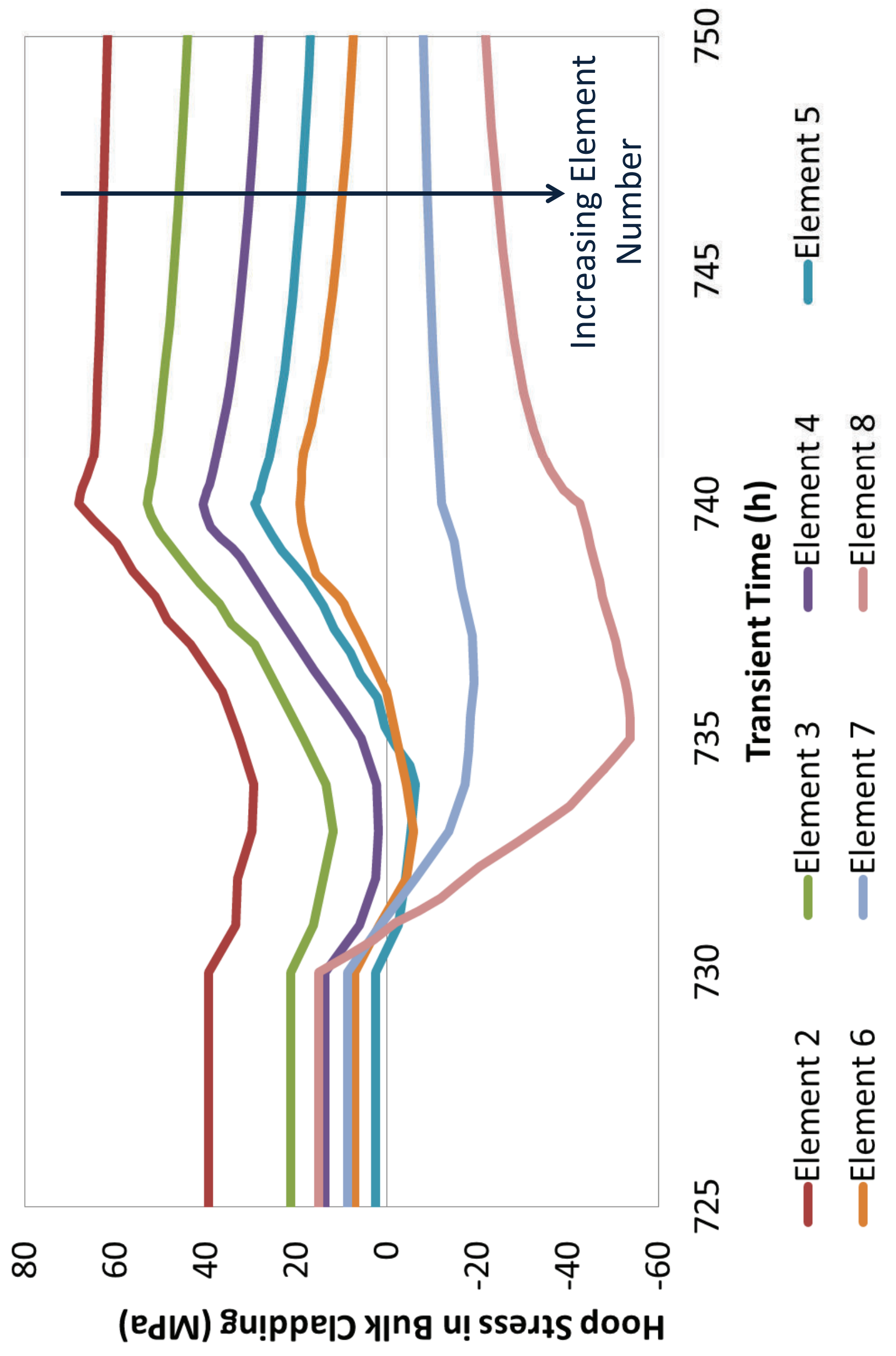




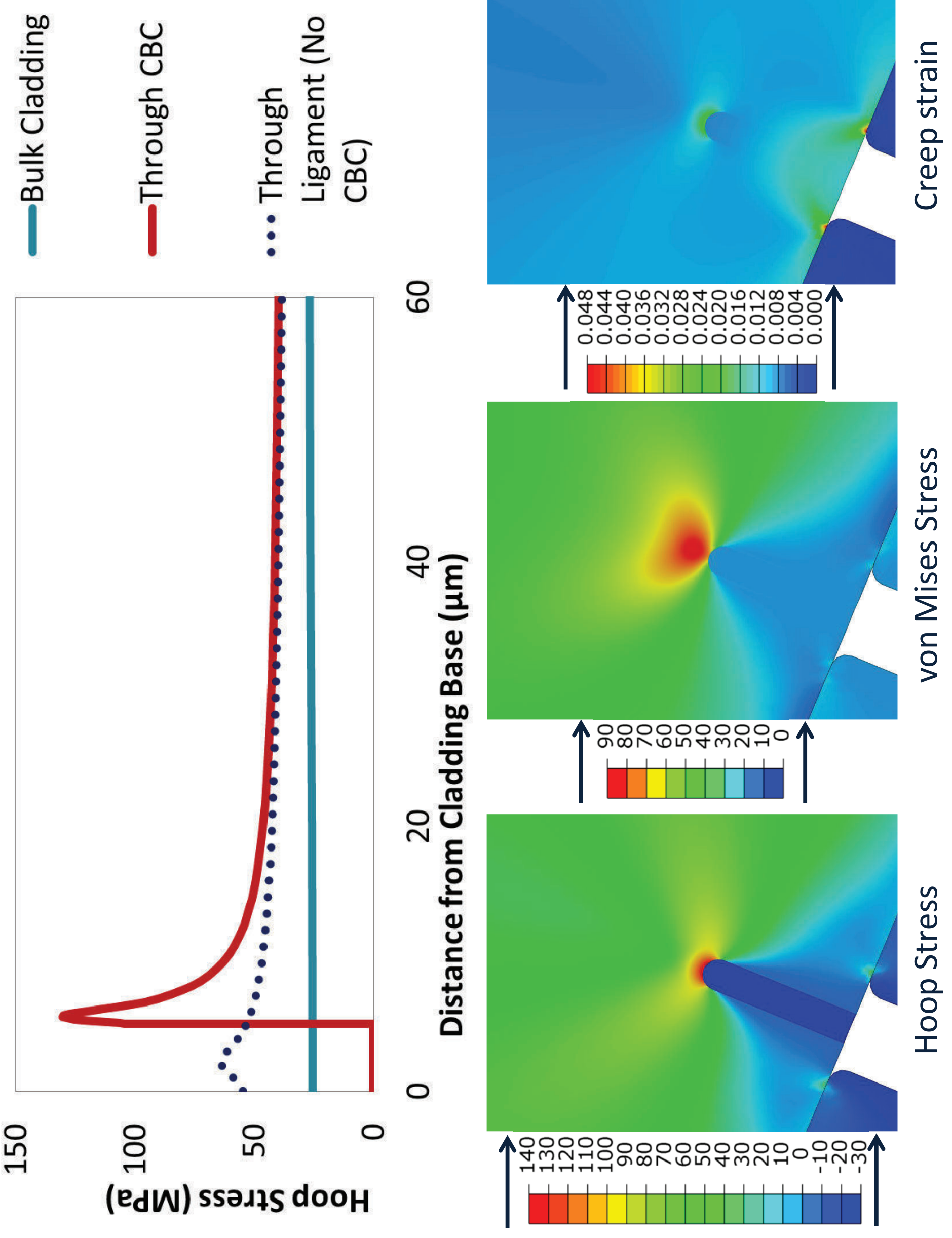




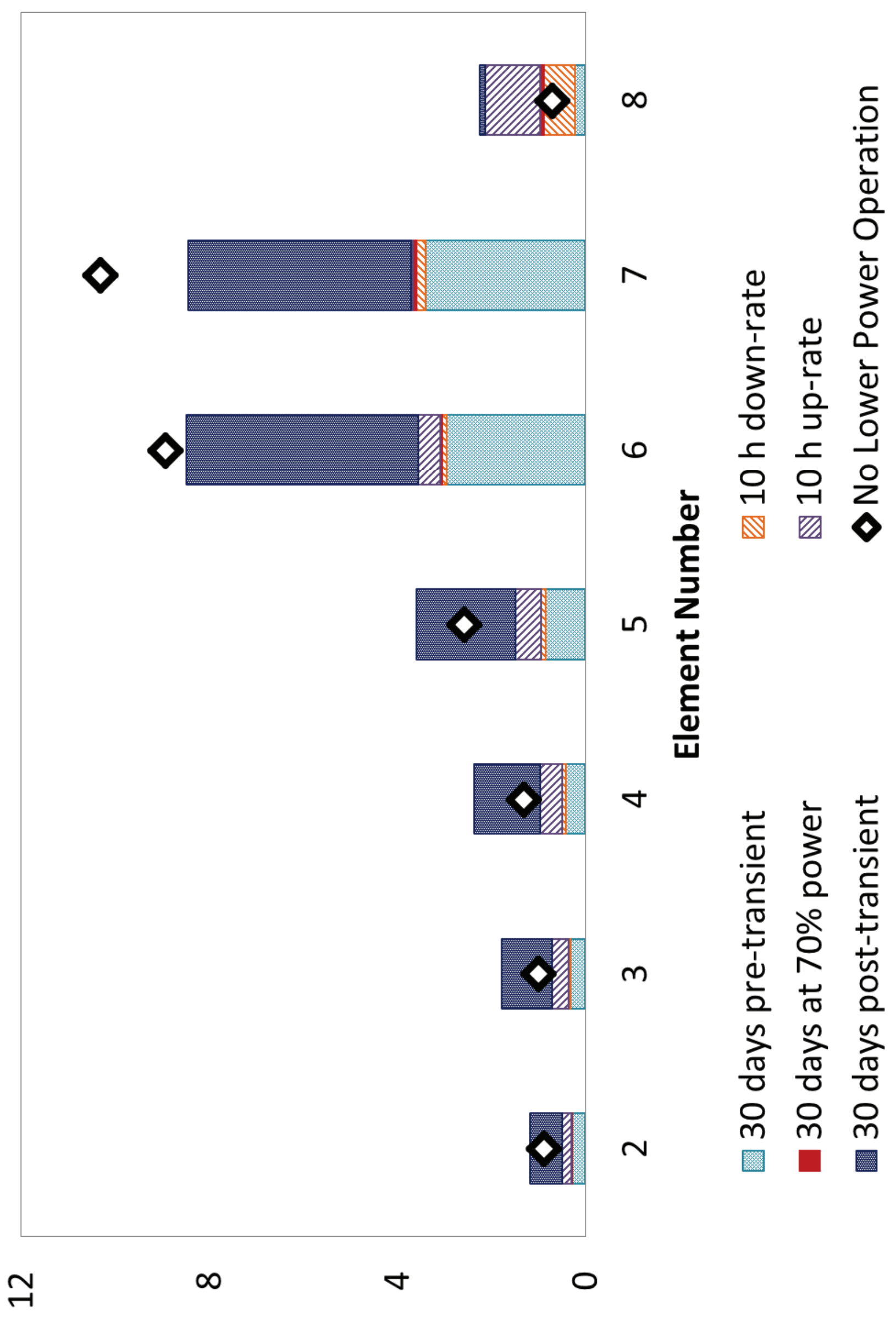

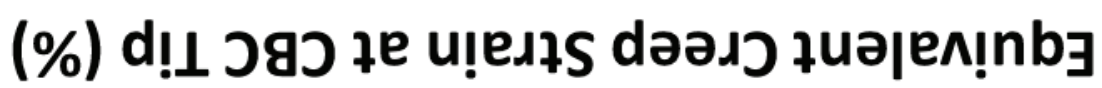




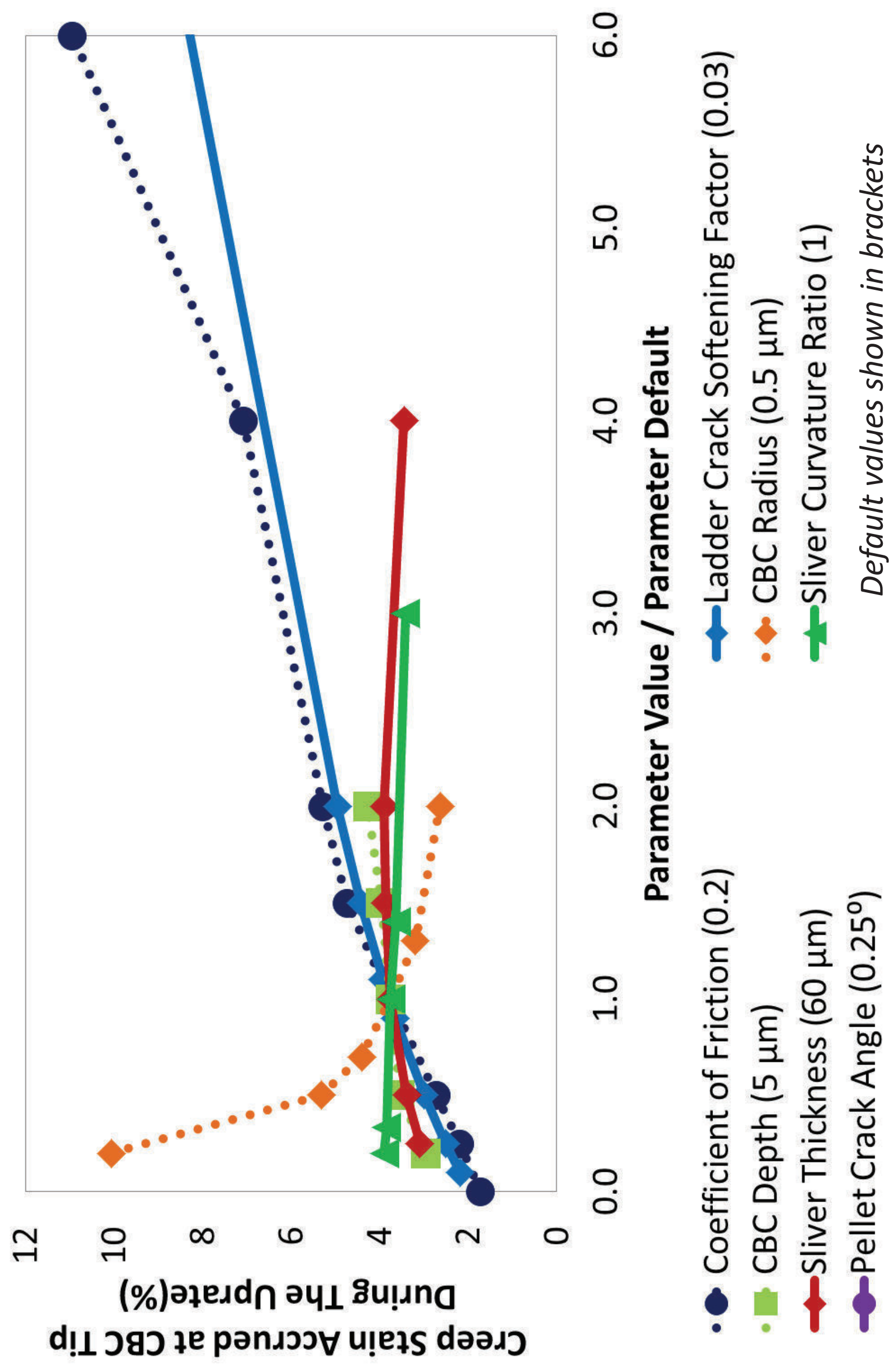




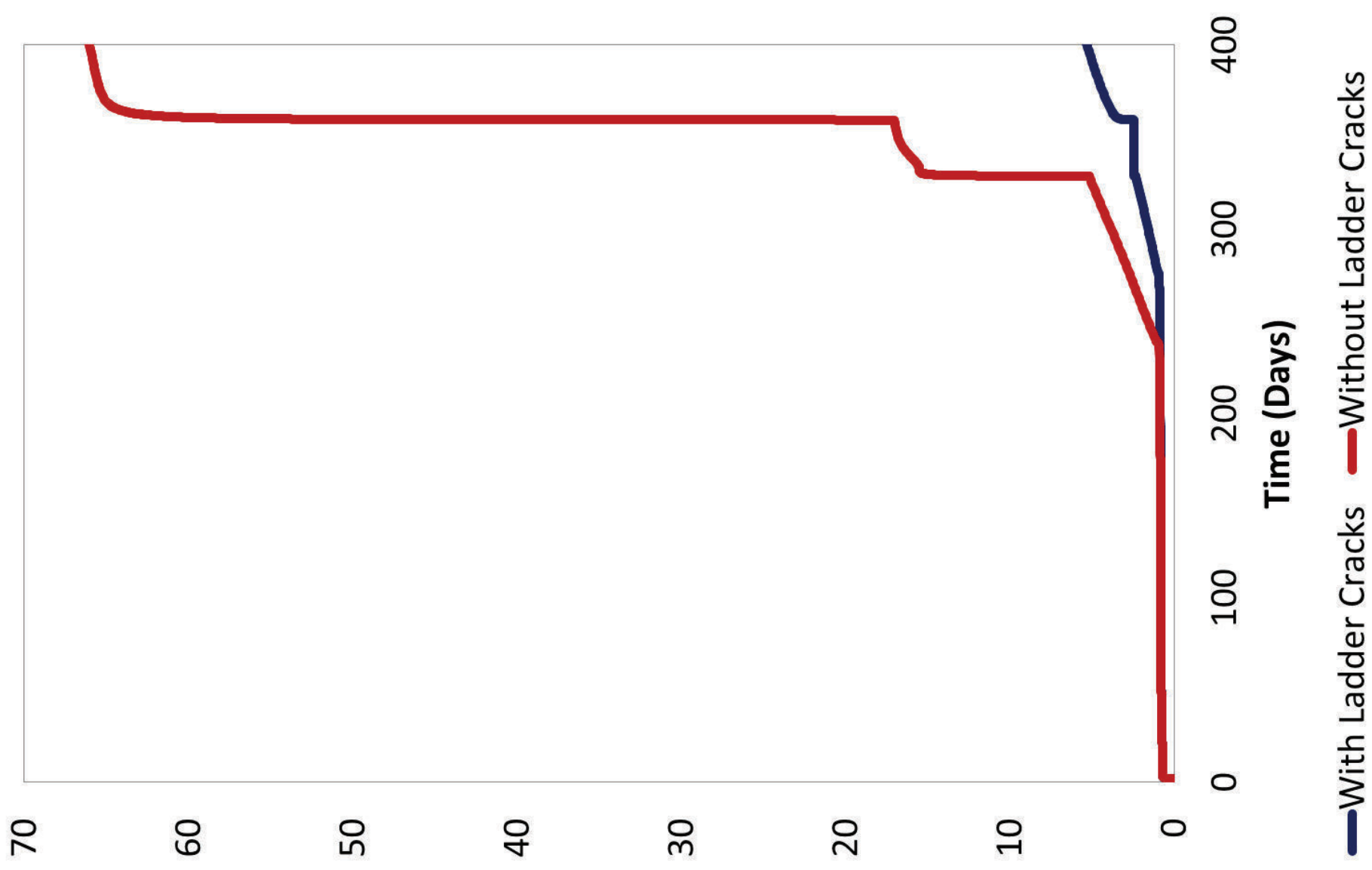

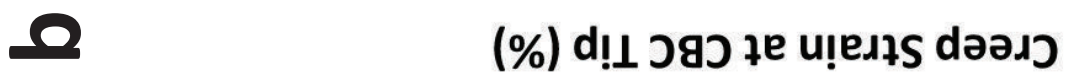

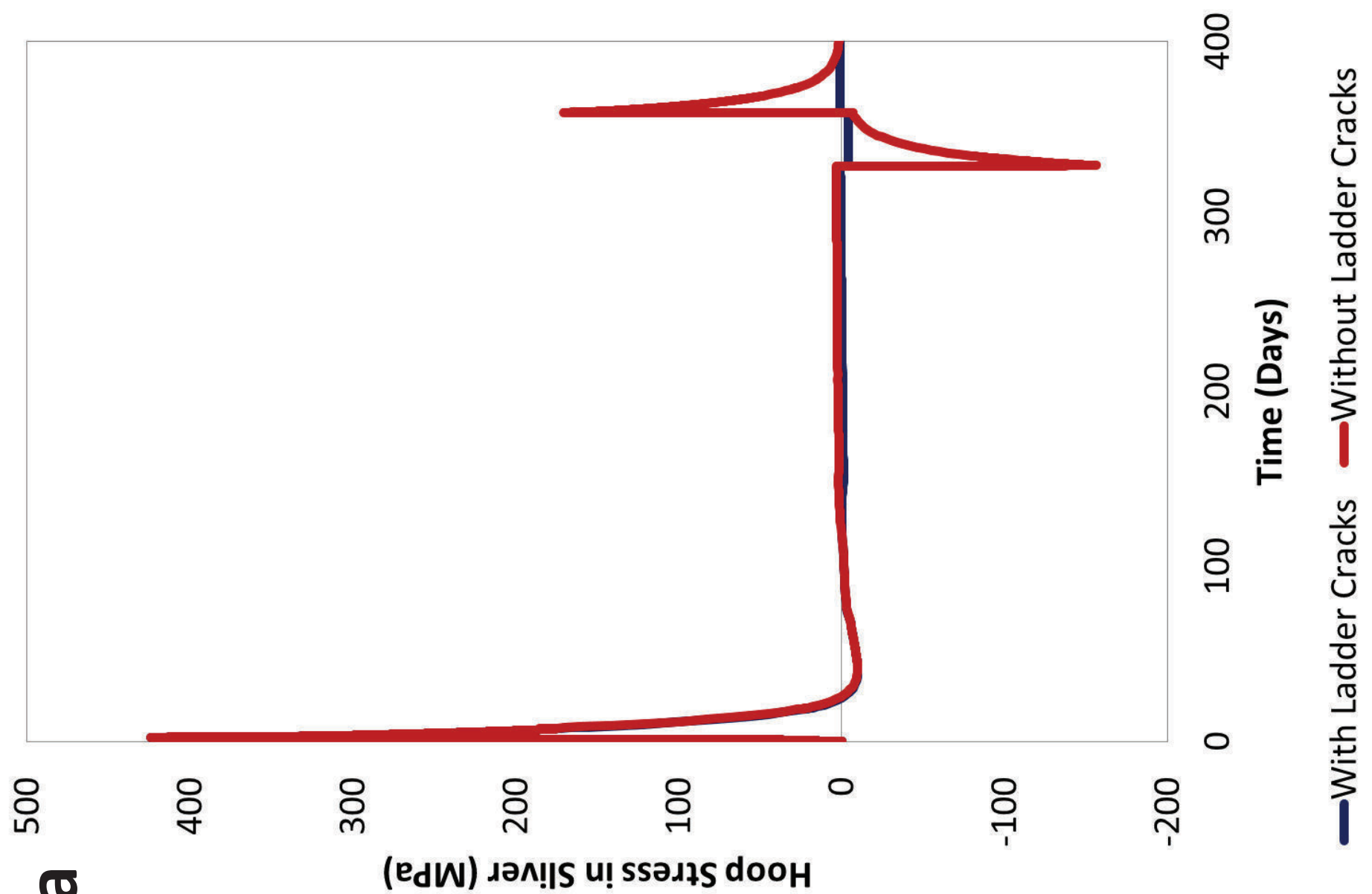



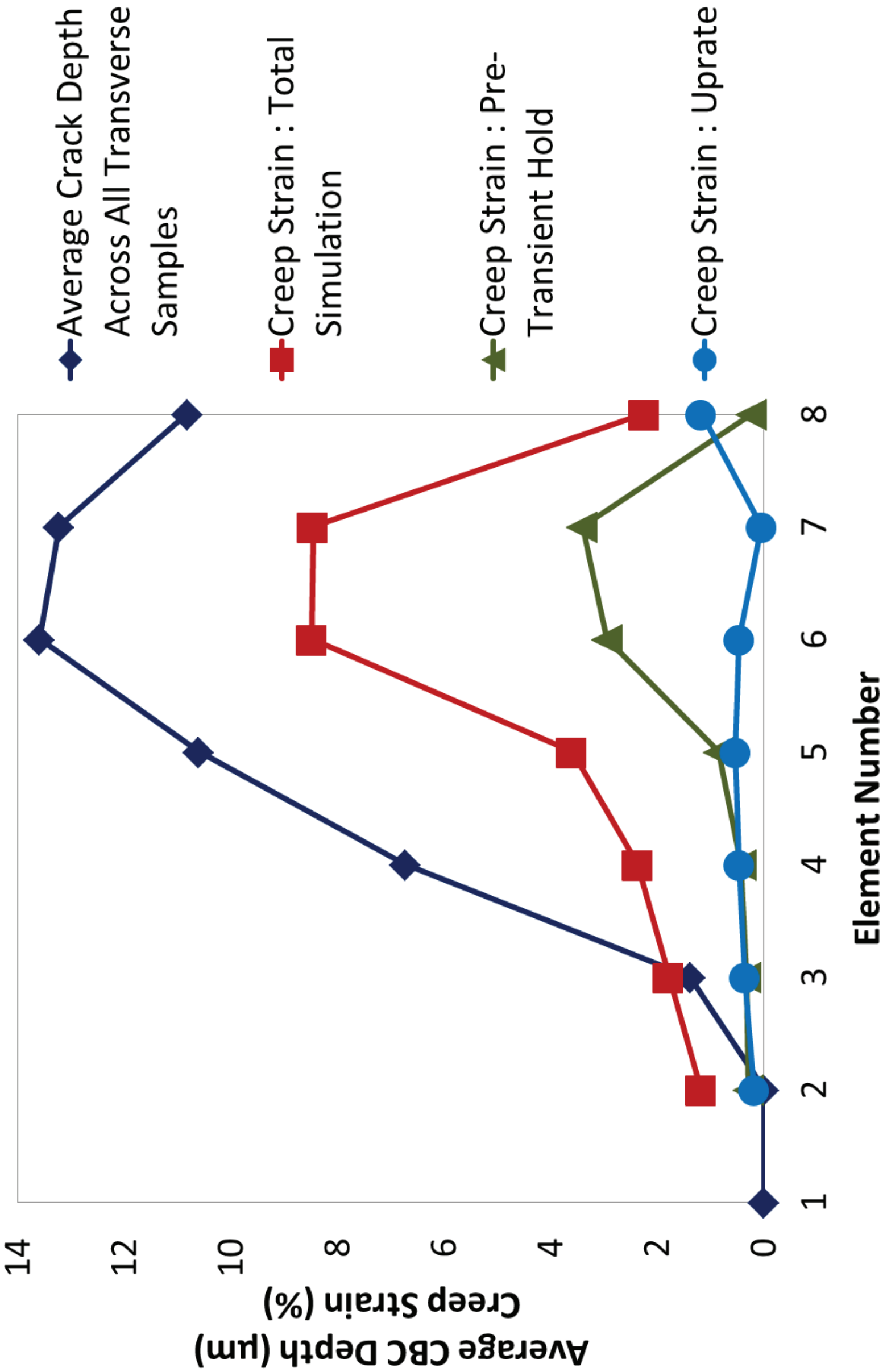